\title{
CrystEngComm
}

\section{Recent advances in the design strategies for porphyrin-based coordination polymers}

Cite this: CrystEngComm, 2014, 16, 7371

Received 23rd April 2014, Accepted 5th June 2014

DOI: $10.1039 / c 4 c e 00854$ e

www.rsc.org/crystengcomm

\author{
Quanzheng Zha, Xing Rui, Tiantian Wei and Yongshu Xie*
}

\begin{abstract}
Porphyrin-based coordination polymers (PCPS) have been investigated for a variety of applications including hydrogen storage, molecular sorption and sensing, photonics, and heterogeneous catalysis. The design and construction of functional PCPs with intriguing structures and promising properties are significant challenges for porphyrin and coordination chemists accompanying huge opportunities. This highlight is focused on recent advances in the design strategies for PCPs, which are summarized as follows: i) introduction of novel multimetal nodes such as multinuclear lanthanides and $\mathrm{Zr}_{6}$ clusters or insertion of active metal ions into the porphyrin core; ii) design and syntheses of novel porphyrinic ligands with multi-carboxyl or pyridyl coordination sites; iii) combination with inorganic polyoxometalates; and iv) encapsulation of porphyrins in cages and post-synthetic modification.
\end{abstract}

\section{Introduction}

Structurally diverse and functionally intriguing coordination polymers (CPs) have been emerging as an attractive research topic in the fields of crystal engineering, solid-state chemistry, and materials science. ${ }^{1}$ CPs are usually synthesized by

Key Laboratory for Advanced Materials and Institute of Fine Chemicals, East China University of Science \& Technology, Shanghai 200237, PR China. E-mail: yshxie@ecust.edu.cn

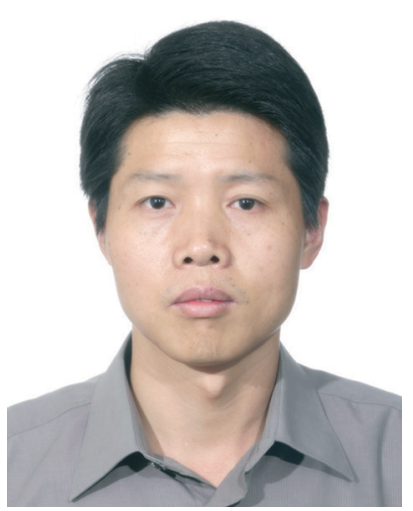

Yongshu Xie
Yongshu Xie received his Ph.D. degree of chemistry from Zhejiang University. Following postdoctoral experience and associate professorship in the University of Science and Technology of China, he successively joined Prof. Xuming Peng's group in National Taiwan University, Prof. Hiroyuki Furuta's group in Kyushu University, and Prof. Katsuhiko Ariga and J. P. Hill's group in the National Institute for Materials Science (Japan) as a research fellow. Now he is a professor in the Institute of Fine Chemicals, East China University of Science and Technology. His research interests are porphyrin chemistry, functional coordination chemistry, and electronic and optical materials based on conjugated organic molecules. the self-assembly of metal ions or metal clusters (nodes) with ligands (linkers), driven by metal-ligand coordination bonds that extend the structures into one, two or three dimensions. Because of the rich variety of metal species, ligands, and guests inside the pores, an enormous number of CPs have been synthesized and reported, ${ }^{2}$ and they are promising for applications in catalysis, ${ }^{3}$ separation, ${ }^{4}$ gas storage ${ }^{5}$ and molecular recognition. ${ }^{6}$

Multidentate chelating and bridging organic ligands with suitably disposed coordinating atoms have been extensively employed for the syntheses of CPs. ${ }^{7}$ Macrocyclic porphyrin structures exist in many biological systems (light harvesting, oxygen transportation, and catalytic systems) with various functions. ${ }^{8}$ In addition, supramolecular chemistry based on porphyrins has attracted widespread interest nowadays. ${ }^{9-13}$

The porphyrin core may coordinate with a metal ion, with the axial positions available for further coordination. Additionally, various coordinating moieties can be rationally introduced to the porphyrin peripheral positions. These diverse coordinating elements can be employed to develop multidentate chelating and bridging ligands for the construction of porphyrin-based coordination polymers (PCPs) with diverse structures and intriguing properties, which can be applied in hydrogen storage, ${ }^{10}$ molecular sorption and sensing, ${ }^{11}$ photonics, ${ }^{12}$ and heterogeneous catalysis. ${ }^{13}$ In this highlight, we will give a short review of recent advances in PCPs, mainly about the design strategies for the construction of PCPs involving coordination with novel multimetal nodes, syntheses of new porphyrin-based ligands, combination with inorganic polyoxometalates, encapsulation of porphyrins in cages and post-synthetic modification strategies. 


\section{Strategy 1: coordination with novel multimetal species or active metal centers}

Tetrakis(4-carboxyphenyl)porphyrin $\left(\mathrm{H}_{2} \mathrm{TCPP}\right)$ and tetrakis(4pyridyl)porphyrin $\left(\mathrm{H}_{2} \mathrm{TPy}\right)$ are two commonly used porphyrinbased ligands (Scheme 1) for the construction of PCPs. ${ }^{14}$ Thus, various multiporphyrin frameworks with different topologies and dimensionalities have been constructed through the coordination of their peripheral carboxyphenyl or pyridyl moieties. Moreover, easy metalation of the porphyrin core provides another opportunity for coordination of two axial ligands. Thus, $\mathrm{H}_{2}$ TCPP and $\mathrm{H}_{2}$ TPyP seem to be almost inexhaustible sources for the construction of either hydrogen-bonding or coordinationdriven PCPs. ${ }^{15}$ In this section, we will make a brief description of recent advances in this respect, with emphasis on novel structures and their applications as heterogeneous catalysts.

\subsection{Coordination of traditional porphyrins with multinuclear lanthanides or $\mathrm{Zr}_{6}$ clusters}

Trivalent lanthanide ions with large radii exhibit high coordination numbers and strong affinity for oxo ligands. Many of the acetate/oxalate salts of trivalent lanthanide ions consist of polynuclear metal ion clusters bridged by several acetate/ oxalate anions, ${ }^{16}$ making them suitable for the construction of novel PCPs.

Goldberg and coworkers ${ }^{17}$ reported the first examples of hybrid porphyrin-lanthanide coordination polymers by reactions of $\mathrm{H}_{2}$ TCPP with $\mathrm{Pr}_{2}$ (oxalate $)_{3}, \mathrm{Nd}_{2}$ (oxalate $)_{3}$, and $\mathrm{Dy}_{2}$ (oxalate) $)_{3}$ hydrated salts. As depicted in Fig. 1a, two $\mathrm{Pr}^{3+}$ cations are bridged by four carboxylates of four different porphyrins. These $\operatorname{Pr}_{2}$ clusters are further interlinked to each other by bridging oxalates, thus affording a polymeric $\left[-\mathrm{Pr}_{2} \text {-(porphyrin)-oxalate- }\right]_{\infty}$ coordination pattern. For the corresponding Dy(III) complex (Fig. 1b), the fundamental tetranuclear synthon consists of four bridged Dy ions connecting to 12 porphyrin molecules distributed between three porphyrin layers. Each of the four porphyrins of the central layer utilizes its carboxylate to bridge the two "inner" Dy ions. Porphyrin species in the first and the third layers either coordinate to the "outer" Dy ions or bridge the outer

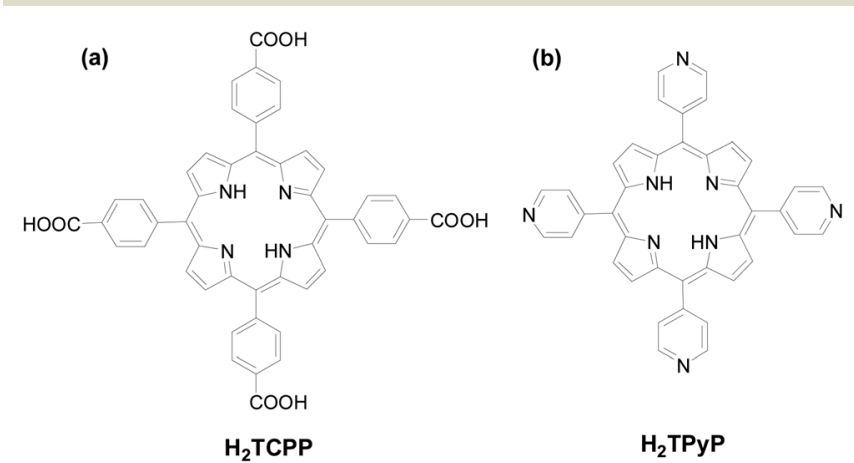

Scheme 1 Chemical structures of two traditional porphyrinic ligands, $\mathrm{H}_{2}$ TCPP (a) and $\mathrm{H}_{2}$ TPyP (b).
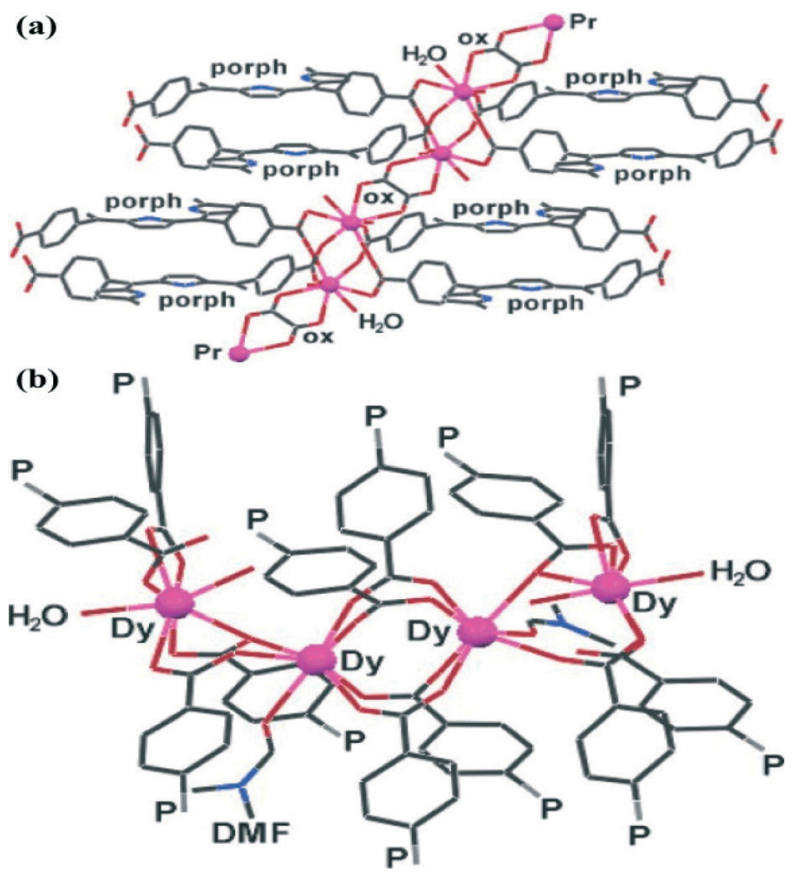

Fig. 1 (a) The continuous coordination pattern of $\mathrm{Pr}_{2}$ clusters, involving the $\mathrm{Pr}$ metal ions, $\mathrm{H}_{2}$ TCPP (only half of the ligand is shown at each site), and the oxalate anions (ox). (b) The tetranuclear coordination synthon showing the binding of 12 porphyrins (organized in three layers) to four Dy ions. Only the terminal carboxyphenyl groups are shown, with "P" representing the remaining porphyrin framework. (Reproduced from ref. 17 with permission, Copyright 2006 American Chemical Society.)

and the inner Dy atoms. These results demonstrated the effective use of the multimetallic lanthanide species in the construction of PCPs based on the tetrafunctional $\mathrm{H}_{2}$ TCPP ligand.

Recently, the $\mathrm{Zr}_{6}$ cluster has attracted increasing attention as one of the most stable building units for the construction of MOFs. A $\mathrm{Zr}^{\mathrm{IV}}$ cation and a carboxylate anion can be classified as a hard acid and a hard base, respectively. ${ }^{18}$ In addition, the high charge density $(\mathrm{Z} / r)$ of $\mathrm{Zr}^{\mathrm{IV}}$ may polarize the carboxylic oxygens, thus affording very strong $\mathrm{Zr}-\mathrm{O}$ bonds with significant covalent character, ${ }^{19}$ making them resistant to water, base, and even acid.

With the elaborate selection of starting materials by Hongcai Zhou and coworkers, ${ }^{20}$ solvothermal reactions of Fe-TCPP, $\mathrm{ZrCl}_{4}$ and benzoic acid in $N, N$-diethylformamide (DEF) for $48 \mathrm{~h}$ at $120^{\circ} \mathrm{C}$ yielded crystals of PCN-222(Fe) (PCN represents porous coordination network), with a framework consisting of square planar porphyrin ligands connected to $\mathrm{Zr}_{6}$ clusters. Each Fe-TCPP moiety coordinates to four 8-connected $\mathrm{Zr}_{6}$ clusters with a twisted angle, forming a 3D network with Kagome-like topology (Fig. 2). Remarkably, the framework is mesoporous, containing large 1D hexagonal open channels with a large diameter of $3.7 \mathrm{~nm}$, ranking among the largest ones for MOFs. ${ }^{21,22}$ Moreover, the framework survived even after immersion in concentrated $\mathrm{HCl}$, which has been rarely observed in MOF materials. In addition, PCN-222(Fe) exhibited biomimetic catalytic activity for a variety of oxidation reactions due to the presence of the active porphyrin centers and large open channels. 
a)

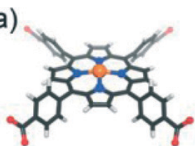

III

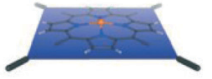

d)

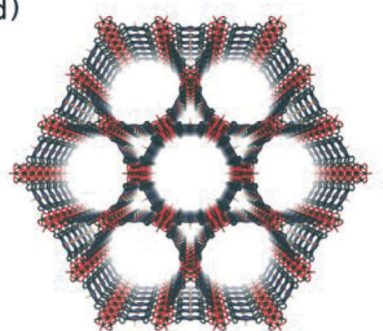

b)

III

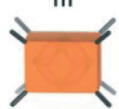

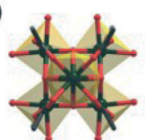

.
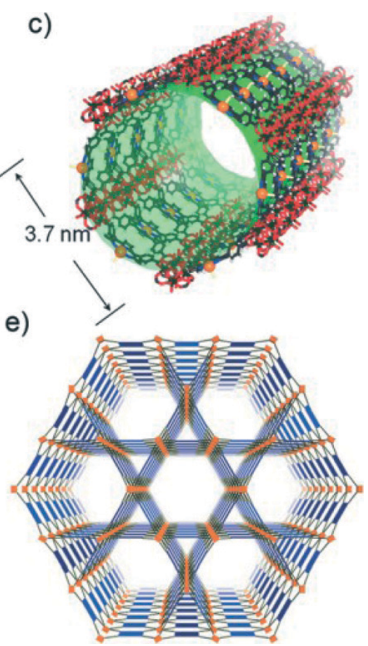

Fig. 2 The crystal structure and underlying network topology of PCN-222(Fe). The Fe-TCPP (a; blue square) is connected to four 8-connected $\mathrm{Zr}_{6}$ clusters ( $\mathrm{b}$; light orange cuboid), generating a 3D network with Kagome-like topology (d, e) and large 1D channels (c; green pillar). Zr: black spheres, C: gray, O: red, N: blue, and Fe: orange. $\mathrm{H}$ atoms have been omitted for clarity. (Reproduced from ref. 20 with permission, Copyright 2012 John Wiley and Sons.)

Solvothermal reactions of $\mathrm{ZrCl}_{4}, \mathrm{H}_{2} \mathrm{TCPP}$, acetic acid, and benzoic acid in DEF at $120{ }^{\circ} \mathrm{C}$ yielded single crystals of PCN-225. ${ }^{23}$ Two kinds of crystallographically independent $\mathrm{Zr}$ atoms are observed and both are coordinated to eight oxygen atoms as depicted in Fig. 3. Six $\mathrm{Zr}$ atoms coordinate with eight $\mu_{3}$-oxygen atoms to afford a cluster with a $\mathrm{Zr}_{6}\left(\mu_{3}-\mathrm{O}\right)_{4}\left(\mu_{3}-\mathrm{OH}\right)_{4}$ core. Each TCPP ${ }^{2-}$ ligand is linked to four such $\mathrm{Zr}_{6}$ clusters, thus generating a 3D porous structure with a $(4,8)$-connected $s q c$ net structure. PCN-225 also demonstrated exceptional chemical stability. The framework remains intact in aqueous solutions within the $\mathrm{pH}$ range of 1 to 11 ; this is the broadest $\mathrm{pH}$ range that PCPs can survive thus far. Furthermore, the central core region of the porphyrin free base demonstrated protonation-deprotonation equilibria, resulting in $\mathrm{pH}$ dependent fluorescence intensity. Interestingly, 7-10 is the most sensitive $\mathrm{pH}$ range for the intensity response, indicating that $\mathrm{PCN}-225$ is promising for $\mathrm{pH}$ sensing, especially in the neutral to weakly basic $\mathrm{pH}$ range.

By carefully varying the ratio of the starting materials and the reagents, a series of new porous porphyrinic zirconium MOFs (denoted as PCN-224) were obtained. ${ }^{24}$ Different from the 12-connected $\mathrm{Zr}_{6}$ cluster observed in UiO-66 (ref. 25) and the 8-connected $\mathrm{Zr}_{6}$ cluster in PCN-222, only six edges of the $\mathrm{Zr}_{6}$ octahedron are bridged by carboxylates from the TCPP ${ }^{2-}$ ligands in PCN-224. By using thrice the amount of $\mathrm{ZrCl}_{4}$ as that for the synthesis of PCN-222, more Zr atoms would compete with each other to coordinate with $\mathrm{TCPP}^{2-}$. Eventually, the increased $\mathrm{Zr}$ : TCPP ratio led to the lower connectivity on the $\mathrm{Zr}_{6}$ cluster and the cluster symmetry was reduced to $D_{3 \mathrm{~d}}$. With the reduced number of carboxylate linkers, PCN-224 contains more free space to generate the 3D open channels (Fig. 4) with a very high BET surface area of $2600 \mathrm{~m}^{2} \mathrm{~g}^{-1}$. It also showed remarkable stability in aqueous
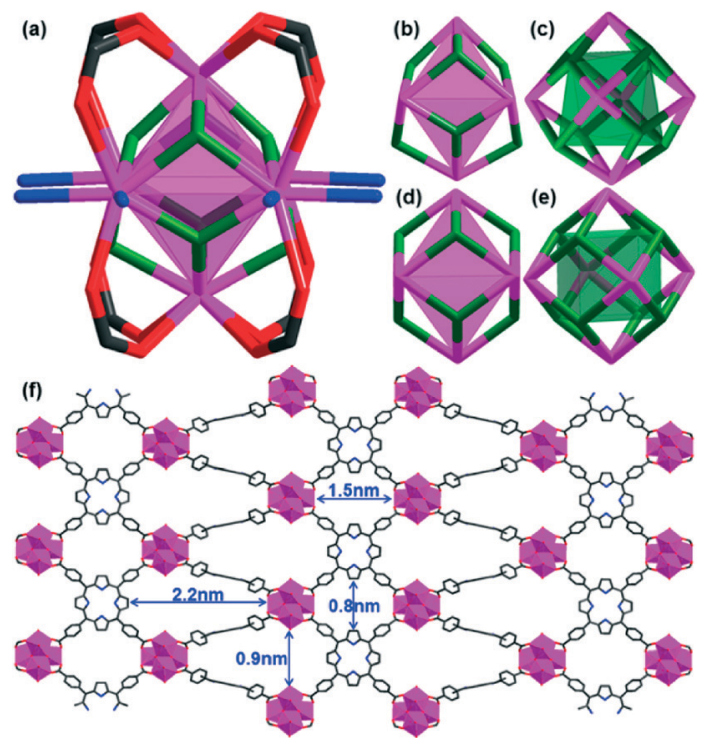

Fig. 3 (a) $\mathrm{Zr}_{6}\left(\mu_{3}-\mathrm{O}\right)_{4}\left(\mu_{3}-\mathrm{OH}\right)_{4}(\mathrm{OH})_{4}(\mathrm{H} 2 \mathrm{O})_{4}(\mathrm{COO})_{8}$ cluster. The oxygen atoms from $\mu_{3}-\mathrm{OH} /-\mathrm{O},-\mathrm{OH} / \mathrm{H}_{2} \mathrm{O}$ and $-\mathrm{COO}$ groups are shown in green, blue and red, respectively; $(b, c)$ an irregular $\mathrm{Zr}_{6}\left(\mu_{3}-\mathrm{O}\right)_{4}\left(\mu_{3}-\mathrm{OH}\right)_{4}$ cluster core in $\mathrm{PCN}-225$, in which six $\mathrm{Zr}$ atoms combine to form an octahedron shaded in pink (b) and eight $\mu_{3}$ oxygen atoms form a highly distorted polyhedron highlighted in green (c). (d, e) An idealized $\mathrm{Zr}_{6}\left(\mu_{3}-\mathrm{OH}\right)_{8}$ cluster core in $\mathrm{PCN}-222$, where the $\mathrm{Zr}_{6}$ octahedron and the $\left(\mu_{3}-O\right)_{8}$ cube are drawn in pink and green, respectively; and (f) a view of the structure of PCN-225 along the $b$ axis with two types of channels. The $\mathrm{Zr}, \mathrm{O}, \mathrm{C}, \mathrm{N}$ atoms are shown in pink, red, gray and blue, respectively. $\mathrm{H}$ atoms have been omitted for clarity. (Reproduced from ref. 23 with permission, Copyright 2013 American Chemical Society.) a)
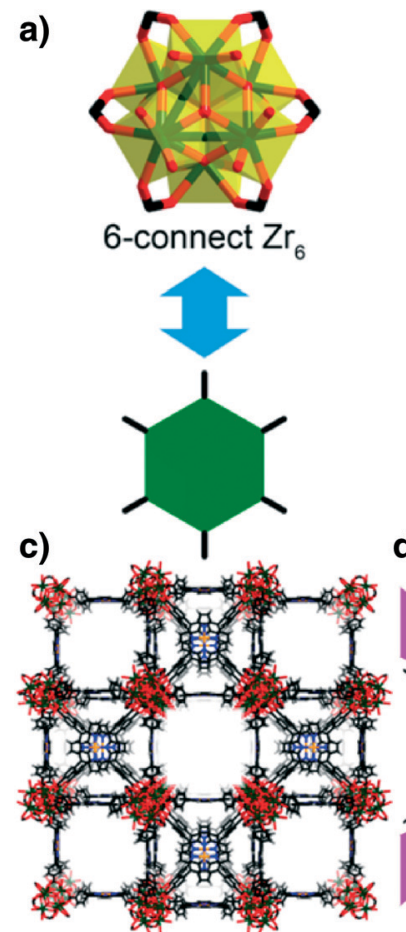

b)

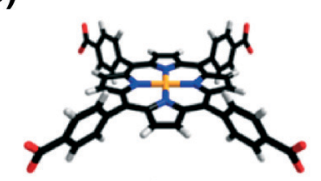

TCPP
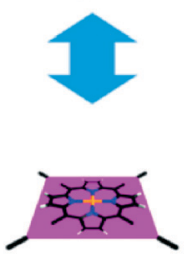

d)

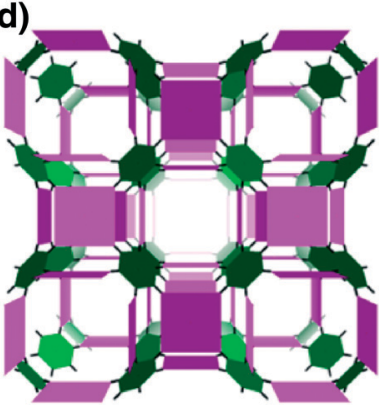

Fig. 4 The 6-connected $D_{3 d}$ symmetric $Z_{6}$ (a) in PCN-224 and tetratopic TCPP ligands (b) with twisted dihedral angles generate a framework with 3D nanochannels (c, d). Colour scheme: $\mathrm{Zr}$, green spheres; C, grey; O, red; N, blue; $\mathrm{Ni}$, orange; and $\mathrm{H}$, white. (Reproduced from ref. 24 with permission, Copyright 2013 American Chemical Society.) 
solutions within a wide $\mathrm{pH}$ range. Moreover, the framework containing Co atoms in the porphyrin centers was observed to be a reusable heterogeneous catalyst for $\mathrm{CO}_{2}$ epoxide coupling reactions.

\subsection{Insertion of active metal ions into the porphyrin core}

$\mathrm{Pd}^{\mathrm{II}}$-porphyrin has been demonstrated to be a catalytically active building block for the construction of functional MOFs by Chuande $\mathrm{Wu}$ et al. ${ }^{26}$ A mixture of Pd-TCPP and $\mathrm{Cd}\left(\mathrm{NO}_{3}\right)_{2} \cdot 4 \mathrm{H}_{2} \mathrm{O}$ in DMF, $\mathrm{MeOH}$ and acetic acid at $80{ }^{\circ} \mathrm{C}$ for ten days yielded crystals of $\left[\mathrm{Cd}_{1.25}\left(\mathrm{Pd}-\mathrm{H}_{1.5} \mathrm{TCPP}\right)\left(\mathrm{H}_{2} \mathrm{O}\right)\right] \cdot 2 \mathrm{DMF}$. This solid incorporates the functional porphyrin ligand with active Pd $^{\text {II }}$ sites in the porous framework. Each Pd-TCPP ligand acts as an octadentate ligand, coordinating with eight Cd atoms from four neighboring Cd chains and assembling into a 3D framework structure (Fig. 5) which contains two kinds of channels with dimensions of $4.61 \times 12.55 \AA^{2}$ and $8.27 \times 9.32 \AA^{2}$ (considering the van der Waals diameters) along the $a$ axis. The framework remains intact upon removing the solvents or exchanging them with other guests, demonstrating its good framework stability. Moreover, the solid shows significant styrene oxidation activity with the advantages of easy separation and good recyclability.

$\mathrm{Sn}^{\mathrm{IV}}$-porphyrins, with good photochemical characteristics for light activation, are easily deactivated by reaction with singlet oxygen atoms. A typical solution to this problem is to immobilize these photoactive sites in the channel walls of porous $\mathrm{MOFs}^{27}$ to realize good photocatalytic performance in heterogeneous phases.

A 3D porous MOF of $\left[\mathrm{Zn}_{2}\left(\mathrm{H}_{2} \mathrm{O}\right)_{4} \mathrm{Sn}^{\mathrm{IV}}(\mathrm{TPyP})\right.$ $\left.(\mathrm{HCOO})_{2}\right] \cdot 4 \mathrm{NO}_{3} \cdot \mathrm{DMF} \cdot 4 \mathrm{H}_{2} \mathrm{O}$ (ref. 28 ) was synthesized by heating a mixture of $\mathrm{Sn}^{\mathrm{IV}}(\mathrm{OH})_{2} \mathrm{TPyP}$ and $\mathrm{Zn}\left(\mathrm{NO}_{3}\right)_{2} \cdot 6 \mathrm{H}_{2} \mathrm{O}$ in DMF and
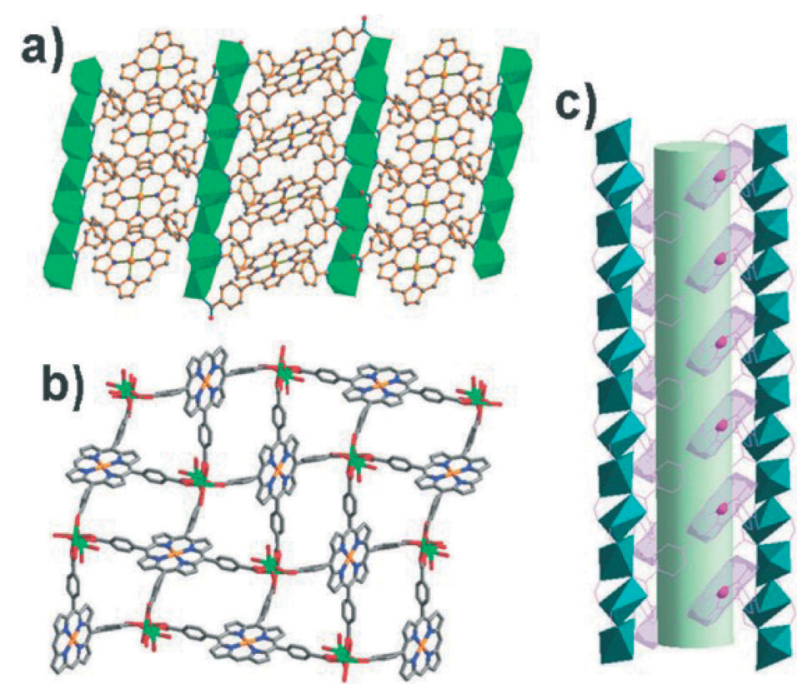

Fig. 5 (a) A view of the 3D framework down the [110] direction, showing the arrangement of the palladium-porphyrins; (b) the 3D framework viewed along the $a$ axis, showing the 1D open channels and the accessible Pd" sites; and (c) the side view of the 1D channel in the porous framework. (Reproduced from ref. 26 with permission from The Royal Society of Chemistry.)
$\mathrm{CH}_{2} \mathrm{Cl}_{2}$ at $50{ }^{\circ} \mathrm{C}$ for five days. Each $\mathrm{Sn}^{\mathrm{IV}}$-TPyP ligand coordinates with four $\mathrm{Zn}$ atoms to afford a $2 \mathrm{D}$ framework structure. The lamellae extend into a $3 \mathrm{D}$ porous network through the connection between the formates and the tin atoms in the porphyrin cores (Fig. 6). It demonstrates remarkable photocatalytic activities for the oxygenation of phenol and sulfides under Xe lamp irradiation with excellent yields and selectivity in heterogeneous phases.

Israel Goldberg et al. reported the coordination of a sixcoordinate Sn-TPyP moiety with multidentate carboxylic acids used as axial ligands. ${ }^{29}$ Five new $\mathrm{Sn}$ (acid) $)_{2}$-TPyP complexes were obtained with the networks sustained by extensive hydrogen bonds between the axial acid ligands (proton donors) and the pyridyl $\mathrm{N}$-sites of the porphyrin (proton acceptors). Combination with different acid ligands resulted in different connectivity features of these five supramolecular assemblies (Fig. 7). When 5-hydroxy-isophthalic acid and trimesic acid ligands were used, the resulting structures presented 1D hydrogen-bonded chains only, as solvation effects prevent interporphyrin interaction in other directions. The combination with 5-amino-isophthalic acid afforded a 2D hydrogen-bonding network, while the reaction with cis-1,3,5-cyclohexane-tricarboxylic acid and 5-bromo-isophthalic acid generated 3D interlinked assemblies.
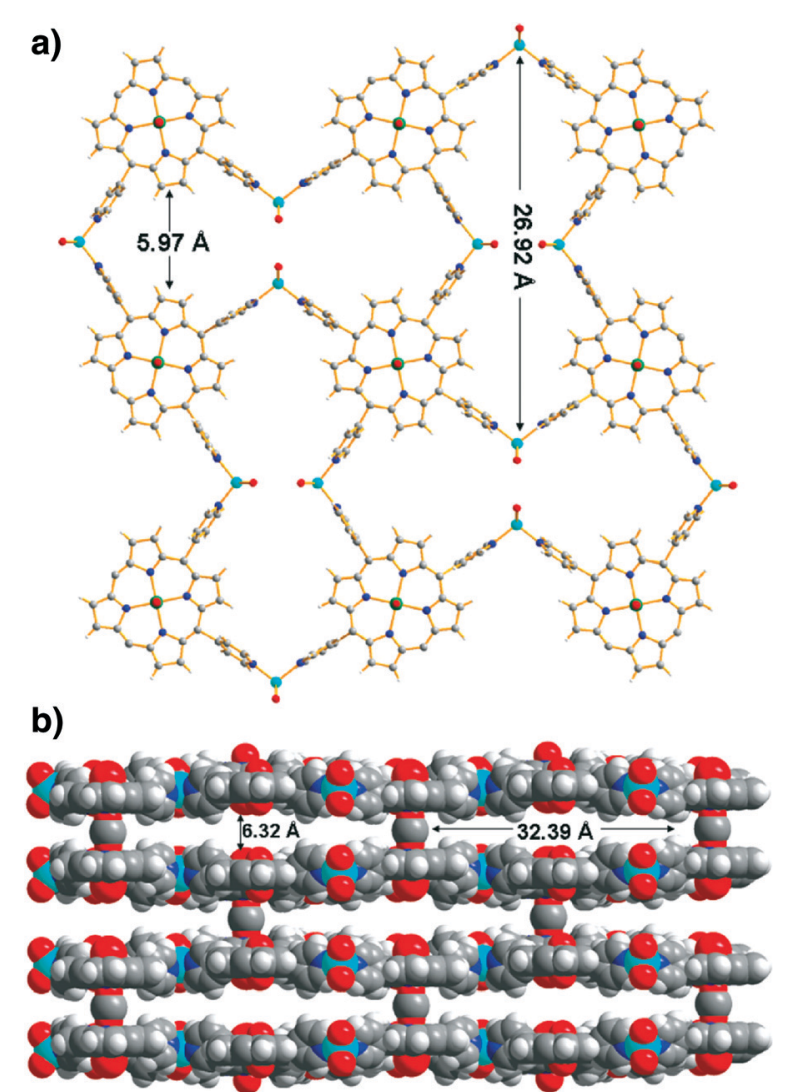

Fig. 6 (a) The lamellar network of $\mathrm{Zn}^{\text {II }}$ atoms linking $\mathrm{Sn}^{\mathrm{IV}}$-porphyrins as viewed along the $c$ axis; and (b) a side view of the 3D network of the lamellae linked by the formate struts along the $b$ axis. (Reproduced from ref. 28 with permission, Copyright 2011 American Chemical Society.) 
a)

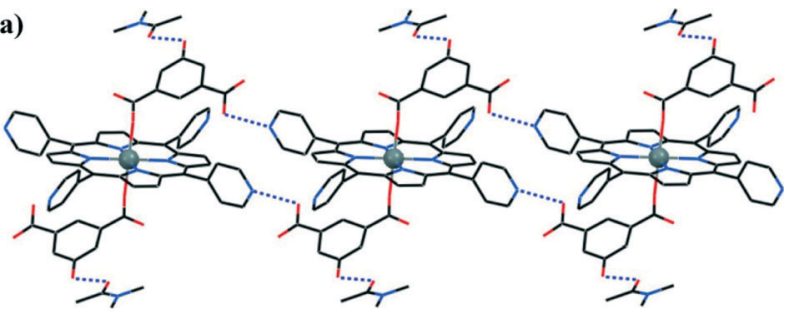

b)

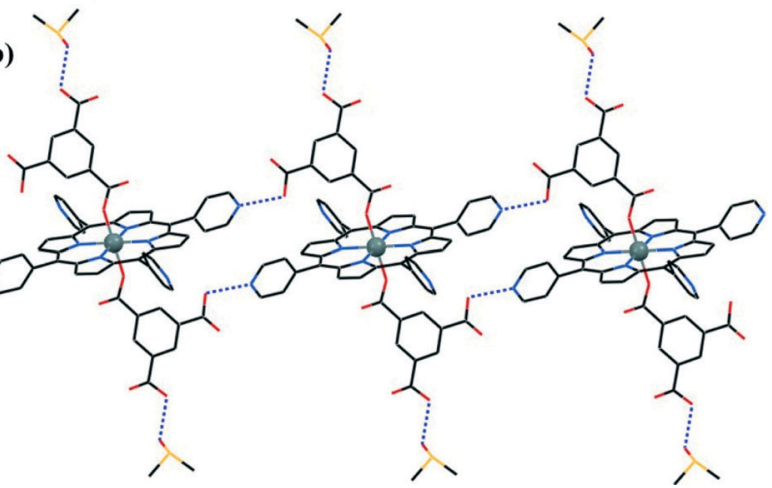

Fig. 7 Self-assembly of the $\left[\mathrm{Sn}-\mathrm{TPyP}\left(\mathrm{A}^{-}\right)_{2}\right]$ units into $1 \mathrm{D}$ hydrogen bonded chains (depicted by dotted lines). Note that the additional hydrogen bonding sites on the axial ligands $(\mathrm{OH}$ and $\mathrm{COOH}$ ) are engaged in hydrogen bonds to the DMA and DMSO solvent moieties, respectively. (Reproduced from ref. 29 with permission, Copyright 2013 American Chemical Society.)

\section{Strategy 2: coordination of novel porphyrin-based ligands}

The design and syntheses of novel porphyrin-based ligands are promising for creating coordination assemblies with novel structures and intriguing properties. Typical porphyrinic ligands recently developed for the construction of PCPs are depicted in Scheme 2. It is noteworthy that the PCPs listed in this section were constructed from only two components, a porphyrinic linker together with discrete metal nodes, without using pillar ligands such as $4,4^{\prime}$-bipyridine, ${ }^{30-42}$ thus leaving the noncoordinated axial positions of the metal centers in the porphyrin cores as active metal sites.

\subsection{Orientational versatility of $\mathrm{H}_{2} \mathrm{~T}^{3} \mathrm{CPP}$ and $\mathrm{H}_{2} \mathrm{~T}^{3} \mathrm{PyP}$ with chair- and table-like conformers}

Following the rich supramolecular chemistry of $\mathrm{H}_{2}$ TCPP and $\mathrm{H}_{2}$ TPyP, tetrakis(3-carboxyphenyl)porphyrin $\left(\mathrm{H}_{2} \mathrm{~T}^{3} \mathrm{CPP}\right)$ and tetrakis(3-pyridyl)porphyrin $\left(\mathrm{H}_{2} \mathrm{~T}^{3} \mathrm{PyP}\right)$ (Scheme 2a, b) have also been demonstrated to form intriguing coordination structures. $^{30-32}$ The four 3-carboxyphenyl or 3-pyridyl arms of the two ligands can assume alternative orientations, positioned either above or below the porphyrin macrocycle, leading to the orientational versatility of the chair- and table-like conformers (Scheme 3). In the "chair" conformer, two adjacent carboxylic moieties are oriented upward and the other two downward, while in the "table" isomer, all four carboxylic arms are oriented in the same direction.

Solvothermal reactions of $\mathrm{H}_{2} \mathrm{~T}^{3} \mathrm{CPP}$ with $\mathrm{Cd}^{2+}$ or $\mathrm{Zn}^{2+}$ ions can afford a molecular box in which two table-like Cd-T ${ }^{3} \mathrm{CPP}$
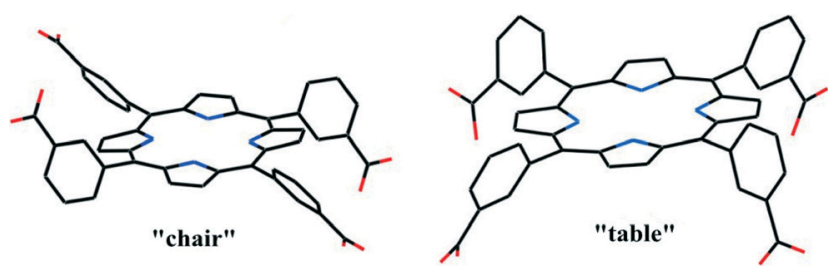

Scheme 3 Illustrations of the chair- and table-like conformers of the $\mathrm{H}_{2} \mathrm{~T}^{3}$ CPP scaffold differing in the relative orientations of the carboxyphenyl "legs". (Reproduced from ref. 30 with permission, Copyright 2013 American Chemical Society.)

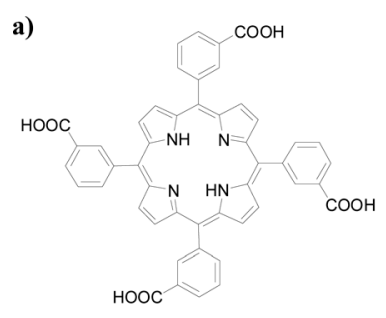

$\mathrm{H}_{2} \mathrm{~T}^{3} \mathrm{CPP}$

e)

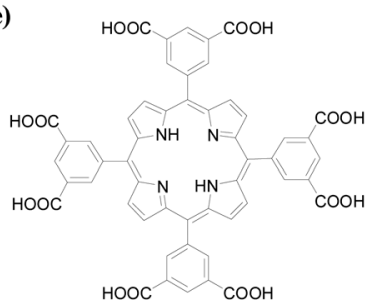

TDCPP

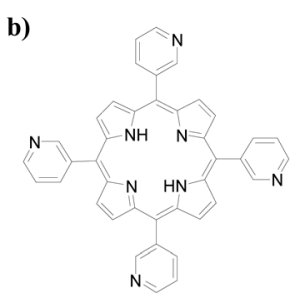

$\mathbf{H}_{2} \mathbf{T}^{3} \mathbf{P y P}$ c)

f)

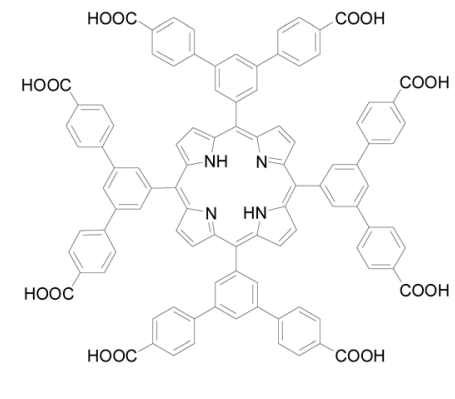

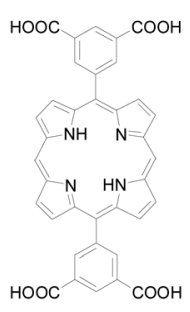

BDCPP d)

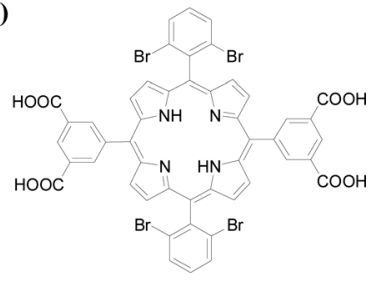

DCDBP

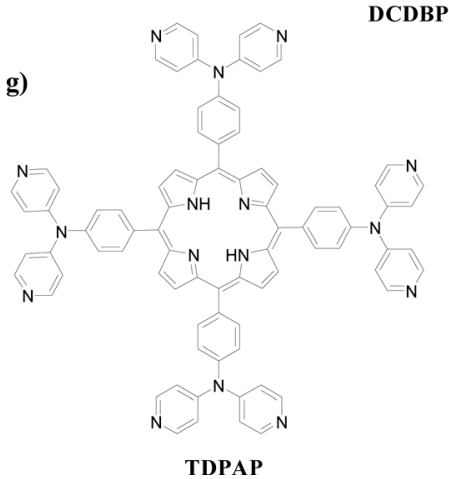

Scheme 2 Chemical structures of the recently developed porphyrin ligands: (a) $\mathrm{H}_{2} T^{3} C P P$, (b) $\mathrm{H}_{2} \mathrm{~T}^{3} \mathrm{PyP}$, (c) BDCPP, (d) DCDBP, (e) TDCPP, (f) TBCPPP, and (g) TDPAP. 


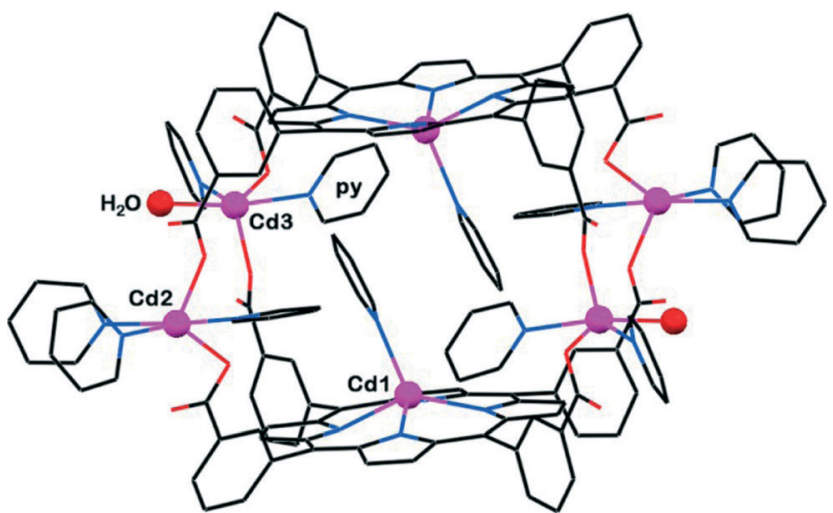

Fig. 8 The discrete (0-D) molecular box-type coordination assembly that involves two table conformers of $\mathrm{Cd}-\mathrm{T}^{3} \mathrm{CPP}$ tessellated into a box-type dimer by four $\left(\mathrm{COO}^{-}\right)-\mathrm{Cd}-\left(\mathrm{COO}^{-}\right)$coordination bridges. (Reproduced from ref. 30 with permission, Copyright 2013 American Chemical Society.)

moieties are linked by four Cd ions (Fig. 8) as well as other coordination polymers with $1 \mathrm{D}$ and $2 \mathrm{D}$ connectivity. ${ }^{30}$ Hydrogen-bonded networks between the chair-like $\mathrm{H}_{2} \mathrm{~T}^{3} \mathrm{CPP} /$ Co- $\mathrm{T}^{3} \mathrm{CPP}$ moieties and various amine ligands were also obtained. While the occurrence of the "table" conformer of $\mathrm{H}_{2} \mathrm{~T}^{3} \mathrm{CPP}$ has been observed for the first time, new supramolecular materials are expected to emerge in the future. These results indicate that the $\mathrm{H}_{2} \mathrm{~T}^{3} \mathrm{CPP}$ scaffold can be effectively used to construct various PCPs through direct multiplecoordination as well as extended hydrogen-bonding networks.

Similar to $\mathrm{H}_{2} \mathrm{~T}^{3} \mathrm{CPP}, \mathrm{H}_{2} \mathrm{~T}^{3} \mathrm{PyP}$ also have attracted extensive attention in recent years. Choe ${ }^{31}$ reported a $\mathrm{H}_{2} \mathrm{~T}^{3}$ PyP-based coordination polymer (MPF-3) with a $2 \mathrm{D}$ interdigitated framework similar to the Cairo pentagonal tessellation. Goldberg ${ }^{32}$ expanded the library of the $\mathrm{H}_{2} \mathrm{~T}^{3} \mathrm{PyP}$-based coordination networks assembled through either endocyclic or exocyclic metal ion linkers, demonstrating the utility of this ligand in the construction of $2 \mathrm{D}$ and 3D PCPs. It is obvious that the conformational versatility of $\mathrm{H}_{2} \mathrm{~T}^{3} \mathrm{CPP}$ and $\mathrm{H}_{2} \mathrm{~T}^{3} \mathrm{PyP}$ enriches the coordination architectures of this scaffold, providing a better choice for the design of novel PCPs.

\subsection{BDCPP and DCDBP with a pair of isophthalates}

The disposition of the coordinating atoms may be changed for the purpose of developing novel PCPs. Ma et al. ${ }^{33}$ reported a porphyrin ligand, 5,15-bis(3,5-dicarboxyphenyl) porphyrin (BDCPP, Scheme 2c), in which two isophthalates were introduced for the construction of a confined nanoscopic polyhedral cage-containing metal-metalloporphyrin framework (MMPF-1) via the reaction of BDCPP with $\mathrm{Cu}$ $\left(\mathrm{NO}_{3}\right)_{2}$ in dimethylacetamide (DMA) at $85{ }^{\circ} \mathrm{C}$. As shown in Fig. 9, sixteen BDCPP ligands are connected with eight paddlewheel second building units (SBUs) to afford a nanoscopic cage: four dicopper paddlewheel SBUs are linked by four isophthalate moieties from four BDCPP ligands to form the top of the cage; they are pillared to four dicopper paddlewheel SBUs at the bottom of the cage through eight BDCPP ligands. The irregular rhombicuboctahedron cage
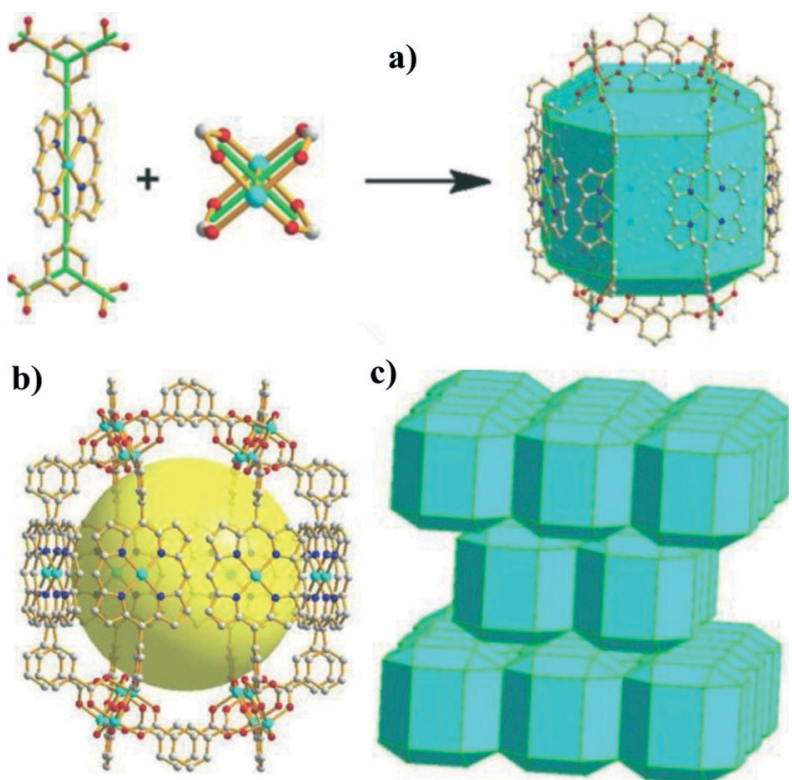

Fig. 9 (a) Illustration of the linking of a BDCPP ligand and a dicopper paddlewheel to form the irregular rhombicuboctahedral cage; (b) a nanoscopic cage enclosed by eight dicopper paddlewheel SBUs and 16 BDCPP ligands (eight are face-to-face porphyrins, and the other eight only provide isophthalate units); and (c) "ABAB" packing of rhombicuboctahedron layers in MMPF-1. (Reproduced from ref. 33 with permission, Copyright 2011 American Chemical Society.)

contains a high density of 16 open $\mathrm{Cu}$ sites and such cages adopt an "ABAB" packing mode, thus constricting its pore size, which facilitates selective adsorption of $\mathrm{H}_{2}$ and $\mathrm{O}_{2}$ over $\mathrm{N}_{2}$ and $\mathrm{CO}_{2}$ over $\mathrm{CH}_{4}$.

Mori et $_{\text {al. }}{ }^{34}$ also investigated the BDCPP ligand; however, they firstly synthesized the building blocks of M-BDCPP $\left[\mathrm{M}=\mathrm{Zn}^{2+}, \mathrm{Ni}^{2+}, \mathrm{Pd}^{2+}, \mathrm{Mn}^{3+} \mathrm{Cl}, \mathrm{Ru}^{2+}(\mathrm{CO})\right]$. The reaction of $\mathrm{Cu}$

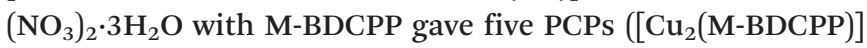
series), which are isostructural regardless of the identity of the central metal in the porphyrin core. There is an internal spherical cavity of $c a .20 \AA$ in diameter (the $\mathrm{Zn}-\mathrm{Zn}$ and $\mathrm{Cu}-\mathrm{Cu}$ distances between the opposite positions are $20.3 \AA$ and $19.6 \AA$, respectively) in the $3 \mathrm{D}$ porous structure of these PCPs, which is surrounded by 16 accessible metal sites (Fig. 10).

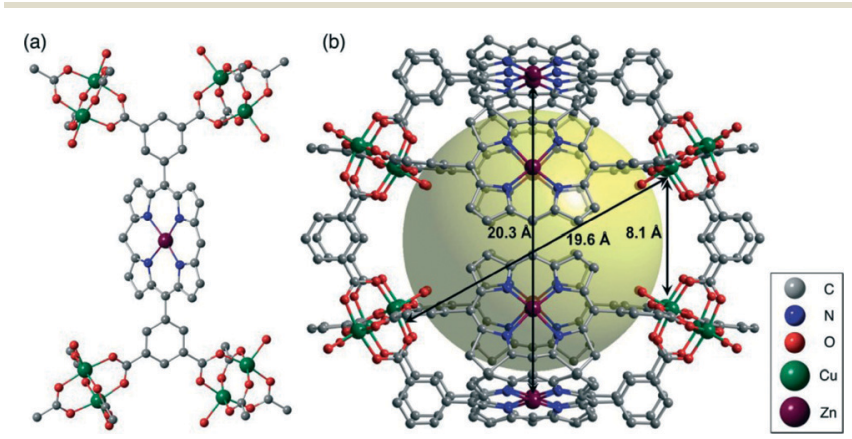

Fig. 10 (a) A Zn-BDCPP moiety of $\left[\mathrm{Cu}_{2}(\mathrm{Zn}-\mathrm{BDCPP})\right]$; and (b) a cage consisting of eight $\mathrm{Zn}-\mathrm{BDCPP}$ ligands and eight paddlewheel $\mathrm{Cu}_{2}$ nodes. $\mathrm{H}$ atoms have been omitted for clarity. (Reproduced from ref. 34 with permission, Copyright 2012 John Wiley and Sons.) 
Impressively, accessible metal sites can be systematically incorporated into the framework without changing the framework topology in this case. The $\left[\mathrm{Cu}_{2}(\mathrm{M}-\mathrm{BDCPP})\right]$ series also exhibit permanent porosity and good $\mathrm{N}_{2}$ and $\mathrm{H}_{2}$ adsorption properties.

A similar ligand, 5,15-bis(3,5-dicarboxyphenyl)-10,20-bis (2,6-dibromophenyl)porphyrin (DCDBP, Scheme 2d) was reported by Ma et al. ${ }^{35}$ MMPF-3 was prepared solvothermally from DCDBP and $\mathrm{Co}\left(\mathrm{NO}_{3}\right)_{2}$, and it can be used as a polyhedral cage-based nanoreactor exhibiting a high density of five catalytically active cobalt centers per $\mathrm{nm}^{3}$. There are three types of polyhedral cages in MMPF-3, i.e., cubohemioctahedron, truncated tetrahedron and truncated octahedron, which are interconnected to form a 3D structure (Fig. 11), exhibiting permanent microporosity confirmed by $\mathrm{CO}_{2}$ adsorption. Due to the high density of active cobalt centers and the porous structure, MMPF-3 demonstrates good performance in catalytic epoxidation of trans-stilbene in terms of both selectivity and overall conversion, indicating that the construction of polyhedral cage-based nanoreactors with a high density of catalytically active metal centers is a useful approach for developing new PCPs as highly efficient heterogeneous catalysts.

\subsection{TDCPP and TBCPPP: innovative octatopic porphyrin ligands}

For the purpose of designing novel PCPs based on porphyrin ligands with the ability to coordinate with more metal centers, more than four carboxylic or pyridyl moieties may be introduced. In this respect, a new octatopic porphyrin ligand, 5,10,15,20-tetrakis(3,5-biscarboxyl-phenyl)porphyrin (TDCPP, Scheme 2e), has been widely investigated by Chuande $\mathrm{Wu}^{36}$ and Shengqian $\mathrm{Ma}$ et $a .^{37,39,40} \mathrm{Wu}$ and coworkers used
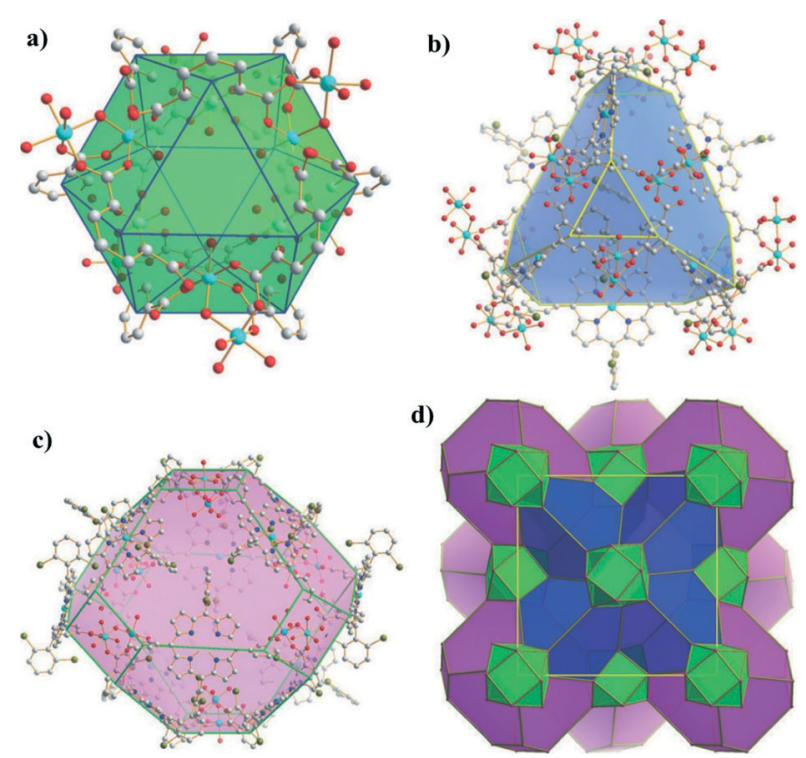

Fig. 11 The three types of polyhedral cages present in MMPF-3: a) cubohemioctahedron, b) truncated tetrahedron, and c) truncated octahedron. d) The 3D structure of MMPF-3 illustrating how its polyhedral cages are connected. (Reproduced from ref. 35 with permission, Copyright 2012 John Wiley and Sons.)

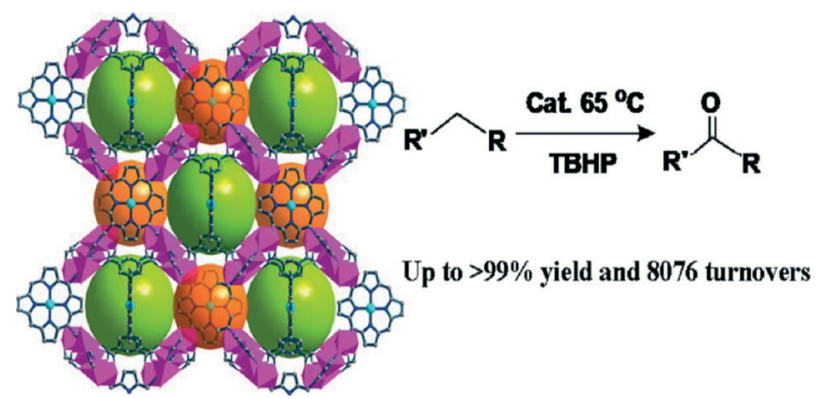

Fig. 12 The porous 3D crystal structure of ZJU-18. It exhibits highly efficient and selective oxidation of ethylbenzene to acetophenone. (Reproduced from ref. 36 with permission, Copyright 2012 American Chemical Society.)

TDCPP to construct three porous metalloporphyrinic frameworks (ZJU-18, ZJU-19, and ZJU-20), ${ }^{36}$ the structures of which are 3-periodic, binodal, edge-transitive nets with the Reticular Chemistry Structure Resource symbol tbo (Fig. 12), showing intercrossed pore windows of about $11.5 \AA$ and pore cages of about $21.3 \AA$ in diameter. These three isostructural MOFs were synthesized by heating a mixture of M-TDCPP $\left(\mathrm{M}=\mathrm{Mn}^{\mathrm{III}} \mathrm{Cl}\right.$ or $\left.\mathrm{Ni}^{\mathrm{II}}\right)$ and $\mathrm{MnCl}_{2}$ or $\mathrm{CdCl}_{2}$ in a mixed solvent of DMF and acetic acid at $80{ }^{\circ} \mathrm{C}$ for one week. Remarkably, ZJU-18 exhibits highly efficient and selective oxidation of ethylbenzene to acetophenone in an almost quantitative yield and a turnover number of 8076 after 48 h. However, the conversion decreases with the increasing size of the substrates. The much lower catalytic conversion for the larger substrates might be attributed to their difficulty in accessing the interior pores of $\mathrm{ZJU}-18$, therefore the catalytic reaction mainly occurs on the exterior surfaces.

TDCPP was also used for the reaction with $\mathrm{Co}\left(\mathrm{NO}_{3}\right)_{2} \cdot 6 \mathrm{H}_{2} \mathrm{O}$ in DMA to construct a novel $(6,8,8)$-connected MOF, MMPF-2, ${ }^{37}$ which contains a rare distorted cobalt trigonal prism SBU, in which three cobalt atoms are bridged by a $\mu_{3}-\mathrm{OH}$ group and six carboxylate groups from six TDCPP ligands (Fig. 13). For the porphyrin ligand, four carboxylates point upwards and the other four point downwards, thus affording a "face-toface" configuration of the porphyrin macrocycles. MMPF-2 possesses permanent microporosity with a high surface area of $2037 \mathrm{~m}^{2} \mathrm{~g}^{-1}$. In addition, a high density of open cobalt centers was observed in the channel walls formed by the

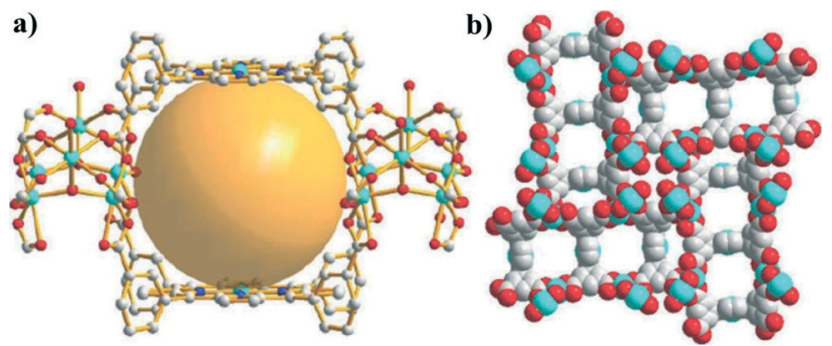

Fig. 13 (a) Three cobalt porphyrins located in the "face-to-face" configuration in MMPF-2; and (b) a space filling model of the three types of channels in MMPF-2 viewed from the $c$ direction. (Reproduced from ref. 37 with permission from The Royal Society of Chemistry.) 
"face-to-face" configuration, resulting in excellent $\mathrm{CO}_{2}$ capture performance with an uptake capacity of $170 \mathrm{~cm}^{3} \mathrm{~g}^{-1}$ at $273 \mathrm{~K}$ and 1 bar.

Metal-organic materials constructed from polyhedral supermolecular building blocks (SBBs) can offer exquisite control over the structures and display useful features such as multiple cage types and relatively narrow pores. ${ }^{38}$ Thus, MMPF-4 $(\mathbf{M}=\mathrm{Zn})$ and MMPF-5 $(\mathrm{M}=\mathrm{Cd})^{39}$ were prepared by solvothermal reactions of TDCPP with $\mathrm{Zn}\left(\mathrm{NO}_{3}\right)_{2}$ and $\mathrm{Cd}$ $\left(\mathrm{NO}_{3}\right)_{2}$, respectively, in DMSO at $135{ }^{\circ} \mathrm{C}$. Fig. 14 illustrates how one face of each TDCPP moiety is metallated with $\mathrm{Zn}$ (II) in situ. In the context of the SBB, Zn-TDCPP serves as a 4-connected node that is connected with triangular paddlewheel $\mathrm{Zn}_{2}\left(\mathrm{CO}_{2}\right)_{3}$ moieties, constructing a small cubicuboctahedron composed of the faces of six Zn-TDCPP moieties linked by eight $\mathrm{Zn}_{2}\left(\mathrm{CO}_{2}\right)_{3}$ units. The resulting cubicuboctahedral SBBs are the first uniform polyhedral SBBs based on porphyrin blocks. The high symmetry augmented pcu topology networks of MMPF-4 and MMPF-5 exhibit two distinct polyhedral cages and are permanently microporous with selective $\mathrm{CO}_{2}$ uptake.

In the structure of $\mathrm{MMPF}-5$, the $\mathrm{Cd}^{\mathrm{II}}$ cation residing within the porphyrin core of TDCPP lies far out of the porphyrin plane, indicative of the weak coordination of $\mathrm{Cd}^{\mathrm{II}}$. These results prompted $\mathrm{Ma}$ et al. $^{40}$ to exchange the large $\mathrm{Cd}^{\mathrm{II}}$ cation with smaller active divalent metal cations. Immersing the crystals of MMPF-5 in a DMSO solution of $\mathrm{Co}\left(\mathrm{NO}_{3}\right)_{2}$ at $85{ }^{\circ} \mathrm{C}$ for two days afforded the $\mathrm{Co}^{\mathrm{II}}$-exchanged MMPF-5(Co). The crystal structure and UV-vis and ICP-MS studies confirmed the complete replacement of $\mathrm{Cd}^{\mathrm{II}}$ with $\mathrm{Co}^{\mathrm{II}}$ occurring
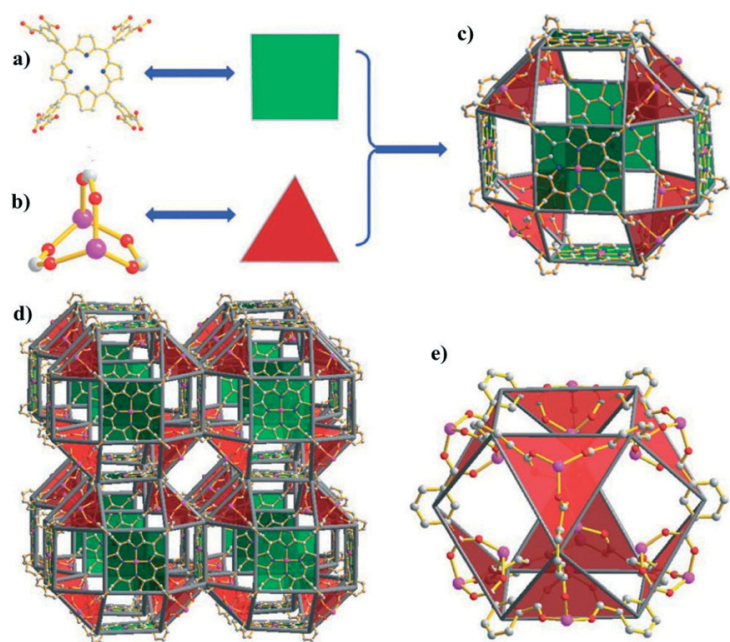

Fig. 14 (a) TDCPP serves as a square molecular building block (MBB); (b) the $\mathrm{Zn}_{2}\left(\mathrm{CO}_{2}\right)_{3}$ paddlewheel moiety serves as a triangular MBB; (c) the small cubicuboctahedron in MMPF-4 is formed by 6 square $\mathrm{Zn}$-TDCPP MBBs and 8 triangular $\mathrm{Zn}_{2}\left(\mathrm{CO}_{2}\right)_{3}$ MBBs; (d) $\mathrm{Zn}$-TDCPP ligands fuse the square faces of small cubicuboctahedra to afford an augmented pcu network with two types of cavities in MMPF-4; and (e) the cage formed between the SBBs can be described as an octahemioctahedron with an internal diameter of $11.189 \AA$ and window dimensions of $8.048 \AA \times 8.048 \AA$ (atom-to-atom distance). (Reproduced from ref. 39 with permission from The Royal Society of Chemistry.) exclusively within the porphyrin macrocycles; however, the $\mathrm{Cd}^{\mathrm{II}}$ cations in the framework remained intact, possibly due to their strong chelation with six carboxylate oxygen atoms. Therefore the small cubicuboctahedral cage in MMPF-5(Co) features the faces of six $\mathrm{Co}^{\mathrm{II}}$-metalated TDCPP moieties that are linked by eight triangular $\mathrm{Cd}\left(\mathrm{CO}_{2}\right)_{3}$ moieties. MMPF-5(Co) demonstrated interesting performance in the catalytic epoxidation of trans-stilbene. All of these findings suggest an easy and versatile method to create PCPs containing different active centers within the same framework structure for heterogeneous catalysis.

Jian Zhang and coworkers ${ }^{41}$ designed a new octatopic porphyrin, tetrakis $\{3,5$-bis[(4-carboxy)phenyl $]$ phenyl $\}$ porphyrin (TBCPPP, Scheme 2f), by inserting a phenyl group between each carboxyl group and the corresponding meso-phenyl ring in the TDCPP molecule in order to increase the rotational flexibility of the carboxyphenyl groups. With this modified ligand, a "pillar-free", highly porous metalloporphyrinic framework $\left\{\left[\mathrm{Zn}_{2}\left(\mathrm{H}_{2} \mathrm{O}\right)_{2}\right]_{2} \cdot\left[(\mathrm{Zn}-\mathrm{TBCPPP})\left(\mathrm{H}_{2} \mathrm{O}\right)_{2}\right]\right\}_{n}$ (UNLPF-1), was generated via solvothermal reaction of TBCPPP and $\mathrm{Zn}$ $\left(\mathrm{NO}_{3}\right)_{2} \cdot 6 \mathrm{H}_{2} \mathrm{O}$ in DMF and acetic acid $(30: 1, \mathrm{v} / \mathrm{v})$ at $80^{\circ} \mathrm{C}$ for 72 h. UNLPF-1 possesses a common type of SBU, namely square paddlewheel $\left[\mathrm{Zn}_{2}(\mathrm{COO})_{4}\left(\mathrm{H}_{2} \mathrm{O}\right)_{2}\right]$. Each SBU links four TBCPPP ligands and each TBCPPP ligand links eight in situ generated SBUs (four above and four below the porphyrin plane) to afford a 3D non-interpenetrated structure (Fig. 15). Two adjacent porphyrin macrocycles, together with four paddlewheel SBUs, form a cage with large dimensions of 14.5 $\AA 23.7 \AA$ (measured between the proximal $\mathrm{Zn}$ centers and the two diagonal SBUs). Impressively, UNLPF-1 exhibits high $\mathrm{CO}_{2}$ adsorption capacity and selectivity for $\mathrm{CO}_{2}$ over $\mathrm{N}_{2}$.

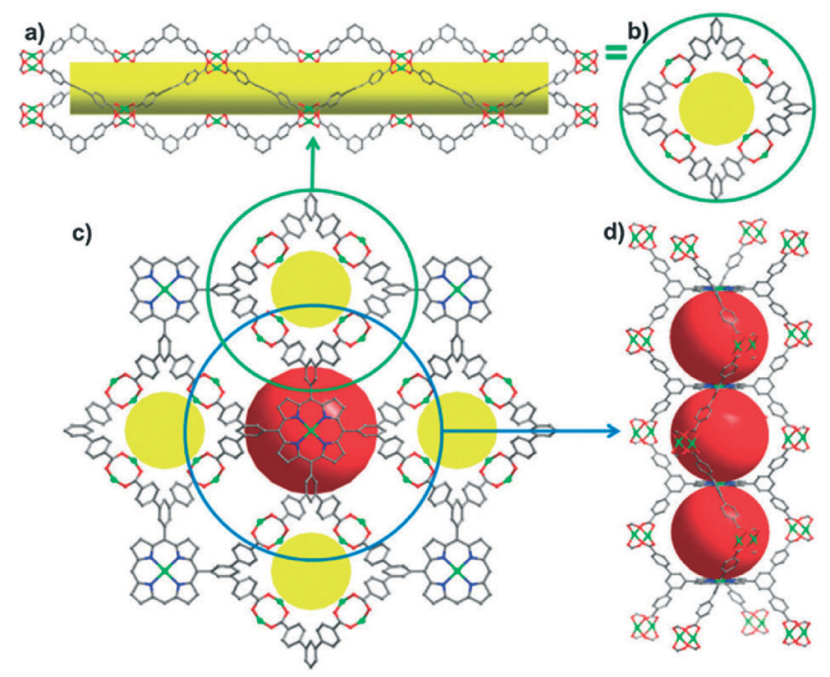

Fig. 15 Side (a) and top (b) views of a single square-shaped tubular supramolecular building block; (c) 3D network connectivity along the [001] direction between the paddlewheels and the $V$-shaped terphenyl arms connecting with the porphyrin linker; and (d) a side view of the 1D eclipsed packing of the porphyrins (cages are represented by red spheres). (Reproduced from ref. 41 with permission from The Royal Society of Chemistry.) 

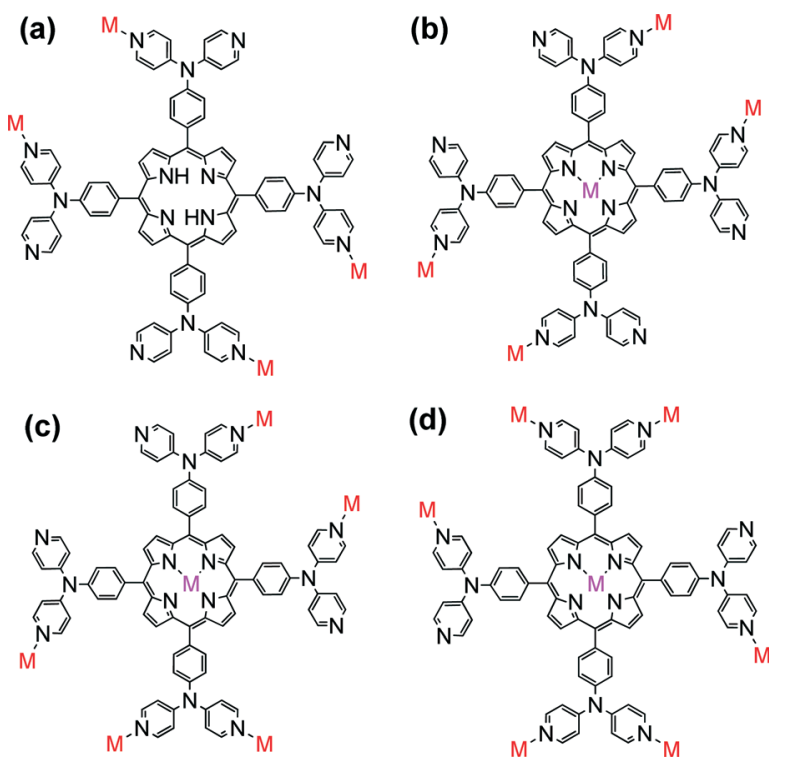

Scheme 4 The demonstrated coordination modes of TDPAP. (Reproduced from ref. 42 with permission, Copyright 2013 American Chemical Society.)

\subsection{TDPAP containing four $4,4^{\prime}$-dipyridylamine moieties}

Recently, Xie's group designed and synthesized a novel porphyrin ligand, 5,10,15,20-tetrakis(4,4-dipyridylamino-phenylene)porphyrin (TDPAP, Scheme $2 \mathrm{~g}$ ), by introducing four 4,4'-dipyridylamine moieties to a porphyrin platform. ${ }^{42}$ The TDPAP ligand can coordinate with 4-7 metal centers (Scheme 4) using its multiple peripheral pyridines and porphyrin core, resulting in a rich structural diversity: a hydrogen-bonded $1 \mathrm{D}$ chains linked by $\left[\left(\mathrm{H}_{2} \mathrm{O}\right)_{2} \mathrm{Cl}_{2}\right]^{2-}$ moieties, a 3D structure formed by the $\pi \cdots \pi$ stacking interactions between interpenetrated 2D networks, a 2D structure with large cavities composed of 50- and 70-membered metallomacrocycles (Fig. 16), a complicated 2D structure linked by zigzag chains, and a stair-like 2D structure containing binuclear $\left[\mathrm{Cd}_{2}\left(\mathrm{CO}_{2}\right)_{4}\right]$ subunits. The 4,4'-dipyridylaminophenylene moieties may rotate around the porphyrin framework, resulting in good conformational flexibility of the TDPAP ligand.

\section{Strategy 3: insertion of polyoxometalates}

Polyoxometalates (POMs) are negatively charged metal-oxide clusters with oxo-rich surfaces and controllable shape and size. ${ }^{43}$ POMs represent a remarkable class of molecular building blocks for the construction of inorganic-organic hybrid materials which has become a rapidly growing area. ${ }^{44}$ Bearing abundant oxygen donors on the surface, POMs are ideal inorganic components to construct hybrid materials with diverse composition and unique properties. In the past decades, such types of inorganic-organic hybrid materials have been applied in catalysis, materials science, and pharmaceutics. ${ }^{45}$ Hence, it is appealing to assemble novel coordination polymers by integrating porphyrin-based organic ligands, transition-metal complex moieties and POMs.
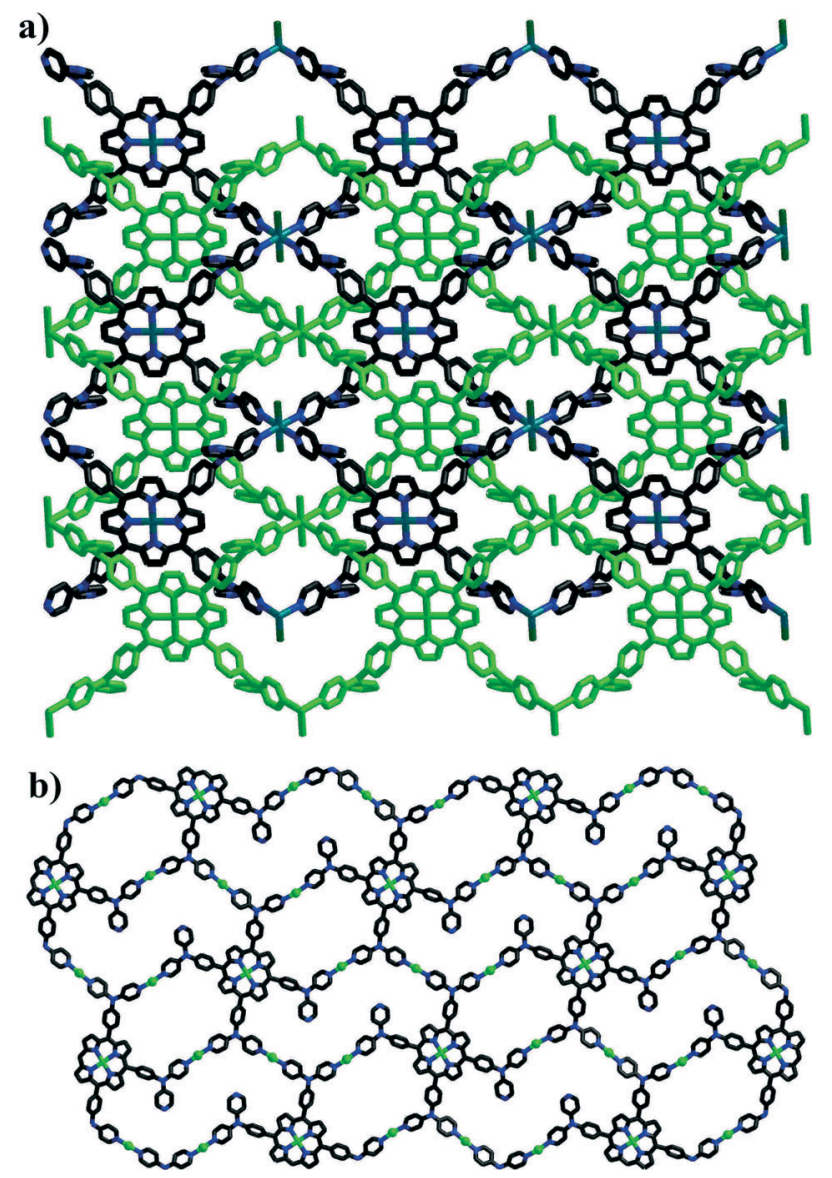

Fig. 16 (a) The interpenetrated 2D coordination networks constructed by TDPAP and $\mathrm{MnCl}_{2}$. (b) The 2D network composed of 50- and 70-membered metallomacrocycles, constructed from TDPAP and $\mathrm{Cu}(\mathrm{OAc})_{2}$. (Reproduced from ref. 42 with permission, Copyright 2013 American Chemical Society.)

Zubieta and co-workers ${ }^{46}$ developed a strategy to construct 3D porphyrin-POM coordination polymers that embedded POMs into the porphyrinic coordination polymer frameworks. Hydrothermal reaction of $\mathrm{MoO}_{3}$, copper nitrate and TPyP in water at $200{ }^{\circ} \mathrm{C}$ afforded a $3 \mathrm{D}$ hybrid of $\left[\mathrm{Cu}(\mathrm{TPyP}) \mathrm{Cu}_{2} \mathrm{Mo}_{3} \mathrm{O}_{11}\right]$. Its structure consists of a tessellated porphyrin network linked through bimetallic $\left\{\mathrm{Cu}_{2} \mathrm{Mo}_{3} \mathrm{O}_{11}\right\}$ oxide chains into a covalently connected $3 \mathrm{D}$ framework. From a similar reaction, $\left[\{\mathrm{Fe}(\mathrm{TPyP})\}_{3} \mathrm{Fe}\left(\mathrm{Mo}_{6} \mathrm{O}_{19}\right)_{2}\right] \cdot x \mathrm{H}_{2} \mathrm{O}$ was obtained, which exhibited a $3 \mathrm{D}$ cationic framework of $\left[\mathrm{Fe}_{4}(\mathrm{TPyP})_{3}\right]_{n}{ }^{4 n+}$ with embedded $\left\{\mathrm{Mo}_{6} \mathrm{O}_{19}\right\}^{2-}$ cluster anions (Fig. 17). The large cavities in these iron-porphyrin cubes are alternately populated by $\left\{\mathrm{Mo}_{6} \mathrm{O}_{19}\right\}^{2-}$ clusters and diffused with disordered water molecules. These two structures illustrate the synergistic interaction of the various structural components and that molybdenum oxide structures may be readily modified by the porphyrin building blocks as well as the porphyrin ligated metal atoms.

The synthesis of metalloporphyrin-POM-based hybrids is extremely difficult, due to the different solubilities of POMs and porphyrins (soluble in water and organic solvents, respectively). To overcome this difficulty, Chuande Wu's group developed a two-step synthesis strategy. ${ }^{47}$ Reaction of $\mathrm{H}_{3} \mathrm{PW}_{12} \mathrm{O}_{40}$ with

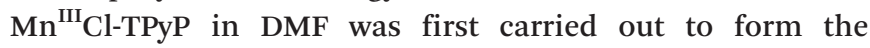




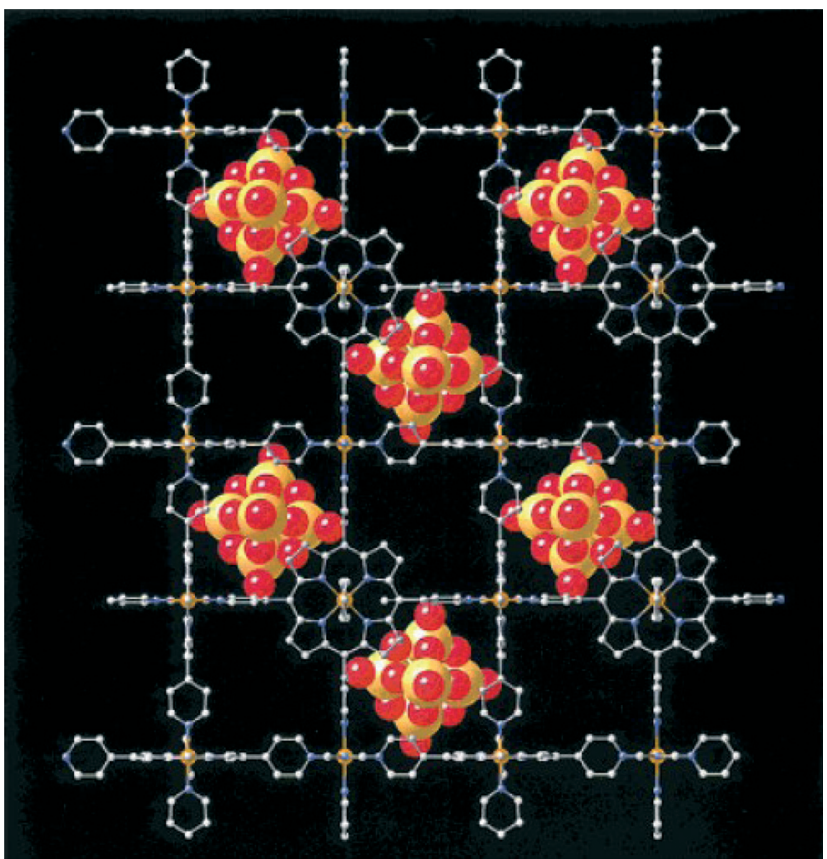

Fig. $17 \mathrm{~A}$ view of the structure of $\left[\{\mathrm{Fe}(\mathrm{TPyP})\}_{3} \mathrm{Fe}\left(\mathrm{Mo}_{6} \mathrm{O}_{19}\right)_{2}\right] \cdot x \mathrm{H}_{2} \mathrm{O}$ parallel to the crystallographic $c$ axis. (Reproduced from ref. 46 with permission, Copyright 1999 John Wiley and Sons.)

zwitterionic complex $\left\{\left[\mathrm{Mn}^{\mathrm{III}}(\mathrm{DMF})_{2} \mathrm{TPyP}^{\mathrm{TP}}\left(\mathrm{PW}_{12} \mathrm{O}_{40}\right)\right\}^{2-}\right.$. The combined components could be readily dissolved both in water and organic solvents (e.g., DMF, $\mathrm{MeOH}$, etc.). Thus, $\left\{\left[\mathrm{Cd}(\mathrm{DMF})_{2} \mathrm{Mn}^{\mathrm{III}}(\mathrm{DMF})_{2} \mathrm{TPyP}\right]\left(\mathrm{PW}_{12} \mathrm{O}_{40}\right)\right\} \cdot 2 \mathrm{DMF} \cdot 5 \mathrm{H}_{2} \mathrm{O}$ was successfully isolated upon reaction of the zwitterionic complex and $\mathrm{Cd}\left(\mathrm{NO}_{3}\right)_{2} \cdot 4 \mathrm{H}_{2} \mathrm{O}$. Its structure is composed of alternating layers of POM anions and porphyrin-containing cationic nets as depicted in Fig. 18. Interestingly, the hybrid material exhibits good capability for scavenging dyes and heterogeneous oxidation of alkylbenzenes with high yields and $100 \%$ selectivity.

\section{Strategy 4: encapsulation of porphyrins in the cages and post-synthetic modification}

Porous metal-organic materials (MOMs) that incorporate reactive species such as metalloporphyrins have drawn increasing attention ${ }^{48}$ because they can demonstrate the physicochemical properties of the metalloporphyrins and their applications as catalysts and dyes while retaining permanent porosity. Such MOMs constructed by selective encapsulation of porphyrins in cages or post-synthetic modification can facilitate gas storage, ${ }^{49,50}$ separation ${ }^{33}$ and catalysis. ${ }^{51}$ In some cases, postsynthetic modification may afford target structures that cannot be obtained by direct reaction of the metal ions with the ligands. In addition, this approach also provides the possibility to immobilize the metalloporphyrins in solid matrices where the macrocycles can be isolated and their catalytic sites are protected in order to inhibit self-dimerization and oxidative degradation. $^{52}$
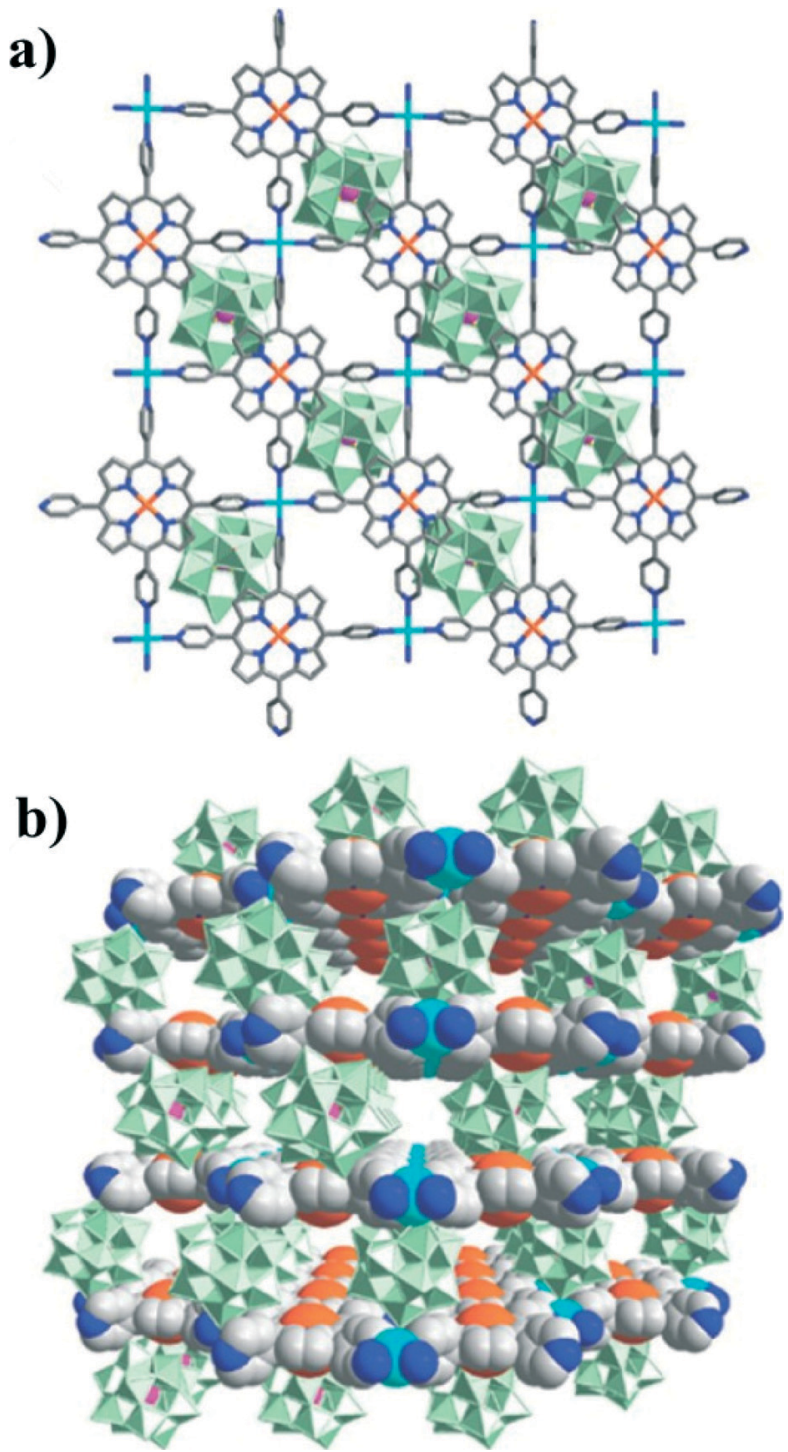

Fig. 18 (a) Arrangement of a single layer of the lamellar framework of $\left[\mathrm{Cd}(\mathrm{DMF})_{2} \mathrm{Mn}^{\prime \prime \prime}(\mathrm{DMF})_{2} \mathrm{TPyP}_{n}{ }^{3 n+}\right.$ and a layer of the $\left[\mathrm{PW}_{12} \mathrm{O}_{40}\right]^{3-}$ polyanions, as viewed along the $c$ axis. (b) A perspective view of the packing diagram of the hybrid material along the [110] direction. Color scheme: $\mathrm{Mn}^{\mathrm{III}}$, orange; $\mathrm{Cd}$, cyan; $\left\{\mathrm{WO}_{6}\right\}$, green octahedra; $\mathrm{P}$, purple; $\mathrm{N}$, blue; and $\mathrm{C}$, gray. DMF molecules and $\mathrm{H}$ atoms have been omitted for clarity. (Reproduced from ref. 47 with permission, Copyright 2012 American Chemical Society.)

Zaworotko's group ${ }^{53}$ reported that reaction of biphenyl3,4',5-tricarboxylate $\left(\mathrm{H}_{3} \mathrm{BPT}\right), \mathrm{CdCl}_{2}$ and TMPyP (TMPyP $=$ meso-tetra( $N$-methyl-4-pyridyl)porphine tetratosylate) afforded porph@MOM-10 (Fig. 19), which contains Cd-TMPyP cations encapsulated in an anionic $\mathrm{Cd}(\mathrm{II})$ carboxylate framework. Thus, TMPyP acts as a template in the generation of porph@MOM-10, which can undergo post-synthetic modification by $\mathrm{Mn}$ (II) or $\mathrm{Cu}$ (II) via single-crystal-to-single-crystal transformation processes. Thus, crystals of porph@MOM-10 were immersed in a methanol solution of $\mathrm{MnCl}_{2}$ and monitored by UV-Vis spectroscopy, which indicated that the conversion of Cd-TMPyP to Mn-TMPyP was complete within one 


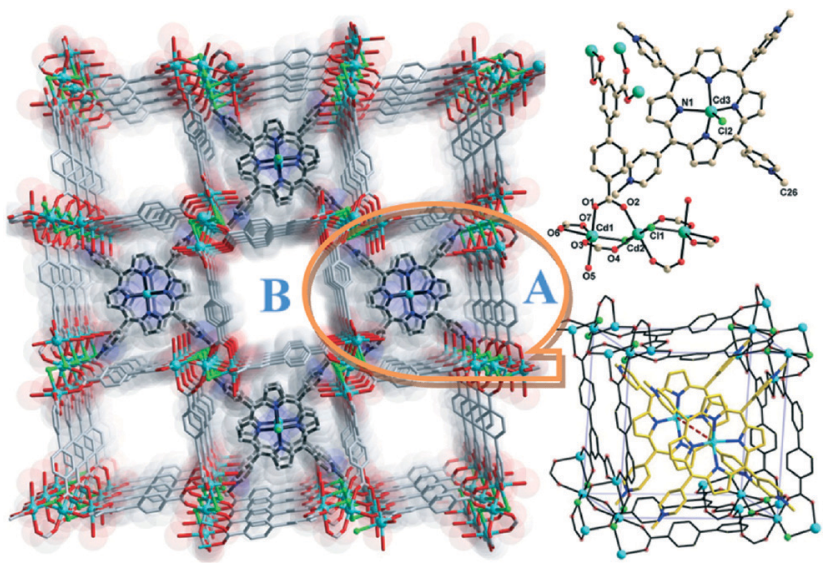

Fig. 19 (Left) Projection of the structure of porphaMOM-10 along the $C$ axis; (above right) the components of the framework and CdTMPyP cations in porph (aMOM-10; (below right) an illustration of CdTMPyP cations trapped in the cuboid boxes of porphaMOM-10. (Reproduced from ref. 53 with permission, Copyright 2012 American Chemical Society.)

week. Atomic absorption studies revealed that framework Cd was almost completely exchanged with $\mathrm{Mn}$ after one month. When immersed in a solution of $\mathrm{CuCl}_{2}$, Cd-TMPyP $\left(\lambda_{\max }=\right.$ $426.4 \mathrm{~nm})$ transformed into Cu-TMPyP $\left(\lambda_{\max }=430.0 \mathrm{~nm}\right)$ but framework $\mathrm{Cd}$ was only partly exchanged with $\mathrm{Cu}$. The resulting $\mathrm{Mn}$ - and $\mathrm{Cu}-$-exchanged variants exhibited catalytic activity for epoxidation of trans-stilbene.

Reaction of $\mathrm{H}_{3} \mathrm{BPT}, \mathrm{Cd}\left(\mathrm{NO}_{3}\right)_{2} \cdot 4 \mathrm{H}_{2} \mathrm{O}$, and TMPyP in DMF- $\mathrm{H}_{2} \mathrm{O}$ yielded a dark green prismatic crystal, porph@MOM-11, ${ }^{54}$ the structure of which is an anionic framework encapsulating cationic porphyrins in alternating channels. Porph@MOM-11 enabled the post-synthetic modification involving single-crystalto-single-crystal transformation processes induced by the addition of metal salts. When it was immersed in a solution of $\mathrm{NaCl}, \mathrm{BaCl}_{2}, \mathrm{MnCl}_{2}$, or $\mathrm{CdCl}_{2}$ for several days, the framework Cd would be partially exchanged with these added metal cations to afford various derivatives (Table 1). The stoichiometric incorporation of the salts allowed a systematic study of the effect of metal cations on gas adsorption. These derivatives exhibit higher selectivity for $\mathrm{CO}_{2}$ versus $\mathrm{CH}_{4}$ compared with the parent porph@MOM-11.

When immersed in $0.05 \mathrm{M} \mathrm{Cu}\left(\mathrm{NO}_{3}\right)_{2}$ in $\mathrm{MeOH}$ for 10 days, porph@MOM-11 (P11) also undergoes single-crystal-to-singlecrystal transformation with its dimetallic $\left[\mathrm{Cd}_{2}(\mathrm{COO})_{6}\right]^{2-}$ units converted into a larger, novel tetrametallic $\left[\mathrm{Cu}_{4} \mathrm{X}_{2}(\mathrm{COO})_{6}(\mathrm{~S})_{2}\right]$ ( $\mathrm{S}=\mathrm{MeOH}, \mathrm{H}_{2} \mathrm{O} ; \mathrm{X}=\mathrm{CH}_{3} \mathrm{O}^{-}, \mathrm{OH}^{-}$), affording P11-Cu with increased unit cell size, pore size, and surface area. ${ }^{55}$ The direct reaction of $\mathrm{Cu}$ salts with $\mathrm{H}_{3}$ BPT did not afford P11-Cu. The use of mixed metal salt solutions $\left(\mathrm{Cd}^{2+} / \mathrm{Cu}^{2+}\right)$ with varying ratios enabled a systematic study of the metal exchange process in P11. When the $\mathrm{Cd}^{2+} / \mathrm{Cu}^{2+}$ ratio was $2: 1$, the $\mathrm{Cd}^{2+}$

Table 1 Structural details of the crystal structures of porphaMOM-11 and its PSM derivatives ${ }^{a}$

\begin{tabular}{|c|c|c|c|c|c|}
\hline & Porph@MOM-11 & $\begin{array}{l}\left.\text { Porph( } \mathrm{cl}^{-}\right) @ M O M-11- \\
\left(\mathrm{Na}^{+}\right)\end{array}$ & $\begin{array}{l}\operatorname{Porph}\left(\mathrm{cl}^{-}\right) @ M O M-11- \\
\left(\mathrm{Ba}^{2+}\right)\end{array}$ & $\begin{array}{l}\text { Porph(cl-)@MOM-11- } \\
\left(\mathrm{Mn}^{2+}\right)\end{array}$ & $\begin{array}{l}\operatorname{Porph}\left(\mathrm{cl}^{-}\right) @ M O M-11- \\
\left(\mathrm{Cd}^{2+}\right)\end{array}$ \\
\hline Site occupancy $^{b}$ & & Na 0.5 & Ba 0.25 & Mn 0.5 & Cd 1 \\
\hline $\mathrm{MBB}_{\mathrm{S}}^{c}$ & & & & & \\
\hline $\begin{array}{l}\text { Channels } \\
\text { incorporating } \\
\text { metal cations }\end{array}$ & & & & & \\
\hline
\end{tabular}

${ }^{a} \mathrm{Cd}$ (turquoise), $\mathrm{Cl}$ (green), $\mathrm{Mn}$ (pink), $\mathrm{Na}$ (lime), Ba (indigo). ${ }^{b}$ Incorporated metals. ${ }^{c} \mathrm{Cd} 1$ is the right $\mathrm{Cd}$ atom and $\mathrm{Cd} 2$ the left $\mathrm{Cd}$ atom. Reproduced from ref. 54 with permission, Copyright 2012 John Wiley and Sons. 


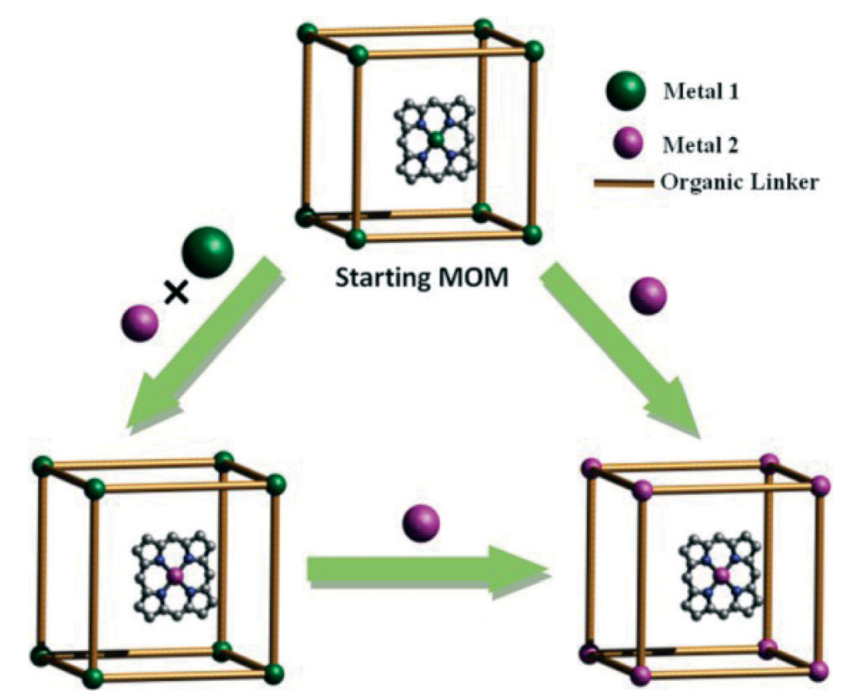

Scheme 5 Metal ion post-synthetic modification in porph@MOMs: (i) partial exchanged with metal 2 in the presence of both metals 1 and 2 (bottom left); (ii) complete exchange with metal 2 (bottom right). (Reproduced from ref. 55 with permission, Copyright 2013 American Chemical Society.)

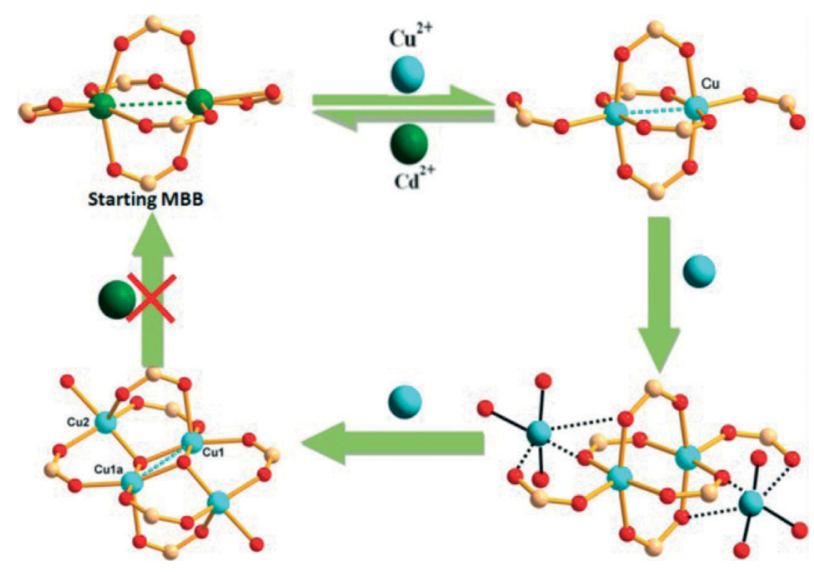

Scheme 6 Possible pathway to form $\left[\mathrm{Cu}_{4} \mathrm{X}_{2}(\mathrm{COO})_{6}(\mathrm{~S})_{2}\right]$ starting from $\left[\mathrm{Cd}_{2}(\mathrm{COO})_{6}\right]^{2-}$ as determined by metal ion exchange and SCXRD. (Reproduced from ref. 55 with permission, Copyright 2013 American Chemical Society.)

ions both in the framework and in the porphyrin cores were fully exchanged with $\mathrm{Cu}^{2+}$. However, when the $\mathrm{Cd}^{2+} / \mathrm{Cu}^{2+}$ ratios were increased to $4: 1$ or $8: 1$, the $\mathrm{Cd}^{2+}$ in the framework were only partially exchanged while the $\mathrm{Cd}^{2+}$ ions in the porphyrin cores were fully exchanged with $\mathrm{Cu}^{2+}$. When the $\mathrm{Cd}^{2+} / \mathrm{Cu}^{2+}$ ratio was $16 / 1$, the framework $\mathrm{Cd}^{2+}$ cations were fully retained while the $\mathrm{Cd}^{2+}$ cations in the encapsulated porphyrins were completely exchanged. These processes are summarized in Scheme 5. Scheme 6 shows how porph@MOMs might undergo the metal exchange in the framework.

\section{Conclusions}

In this highlight, we briefly summarized recent advances in the synthesis, functionalization, and applications of PCPs.
We have described several crystal engineering strategies that can be successfully applied to the construction of extended PCPs: i) introduction of novel multimetal nodes like the lanthanides and $\mathrm{Zr}_{6}$ clusters or insertion of active metal ions into the porphyrin core; ii) design and synthesis of new porphyrinic ligands with multi-carboxyl or pyridyl coordination sites; iii) combination with inorganic polyoxometalates; and iv) encapsulation of porphyrins in cages and postsynthetic modification. In conclusion, porphyrin-based coordination polymers will definitely receive increasing attention due to their diverse and attractive structures in addition to their interesting properties in various areas, especially in heterogeneous catalysis, gas storage, and separation.

\section{Acknowledgements}

This work was financially supported by the NSFC (91227201), the Program for Professor of Special Appointment (Eastern Scholar) at the Shanghai Institutions of Higher Learning, the Program for New Century Excellent Talents in University (NCET-11-0638), and the Fundamental Research Funds for the Central Universities (WK1013002).

\section{References}

1 (a) J. P. Zhang, X. C. Huang and X. M. Chen, Chem. Soc. Rev., 2009, 38, 2385-2396; (b) O. M. Yaghi, M. O'Keeffe, N. W. Ockwig, H. K. Chae, M. Eddaoudi and J. Kim, Nature, 2003, 423, 705; (c) J. Lee, O. K. Farha, J. Roberts, K. A. Scheidt, S. T. Nguyen and J. T. Hupp, Chem. Soc. Rev., 2009, 38, 1450-1459; (d) A. M. Spokoyny, D. Kim, A. Sumrein and C. A. Mirkin, Chem. Soc. Rev., 2009, 38, 1218-1227; (e) J. R. Long and O. M. Yaghi, Chem. Soc. Rev., 2009, 38, 1213-1214; $(f)$ C. X. Ding, J. Ni, Y. H. Yang, S. W. Ng, B. W. Wang and Y. S. Xie, CrystEngComm, 2012, 14, 7312; $(g)$ Y. S. Xie, J. Ni, F. K. Zheng, Y. Cui, Q. G. Wang, S. W. Ng and W. Zhu, Cryst. Growth Des., 2009, 9, 118; (h) Y. Y. Tang, C. X. Ding, S. W. Ng and Y. S. Xie, RSC Adv., 2013, 3, 18134; (i) T. Yamada, K. Otsubo, R. Makiura and H. Kitagawa, Chem. Soc. Rev., 2013, 42, 6655-6669.

2 (a) T. Uemura, N. Yanai and S. Kitagawa, Chem. Soc. Rev., 2009, 38, 1228-1236; (b) F. H. Zeng, J. Ni, Q. G. Wang, Y. B. Ding, S. W. Ng, W. H. Zhu and Y. S. Xie, Cryst. Growth Des., 2010, 10, 1611; (c) C. Ding, X. Li, Y. Ding, X. Li, S. W. Ng and Y. Xie, Cryst. Growth Des., 2012, 12, 3465; (d) J. Heine and K. M. Buschbaum, Chem. Soc. Rev., 2013, 42, 9232-9242; (e) C. Ding, X. Rui, C. Wang and Y. S. Xie, CrystEngComm, 2014, 16, 1010-1019; $(f)$ C. Ding, C. Gao, S. Ng, B. Wang and Y. S. Xie, Chem. - Eur. J., 2013, 19, 9961-9972.

3 S. H. Cho, B. Ma, S. T. Nguyen, J. T. Hupp and T. E. Albrecht Schmitt, Chem. Commun., 2006, 2563.

4 J. L. C. Rowsell and O. M. Yaghi, Angew. Chem., Int. Ed., 2005, 44, 4670 .

5 Y. S. Bae, O. K. Farha, A. M. Spokoyny, C. A. Mirkin, J. T. Hupp and R. Q. Snurr, Chem. Commun., 2008, 4135. 
6 P. Horcajada, C. Serre, M. Vallet-Regí, M. Sebban, F. Taulelle and G. Férey, Angew. Chem., Int. Ed., 2006, 45, 5974.

7 (a) W. Q. Kan, J. Yang, Y. Y. Liu and J. F. Ma, CrystEngComm, 2012, 14, 6271; (b) J. C. Hierso, R. Smaliy, R. Amardeila and P. Meuniera, Chem. Soc. Rev., 2007, 36, 1754.

8 (a) T. K. Chandrashekar and S. Venkatraman, Acc. Chem. Res., 2003, 36, 676; (b) E. Rose, A. Lecas, M. Quelquejeu, A. Kossanyi and B. Boitrel, Coord. Chem. Rev., 1998, 178, 1407; (c) M. O. Senge and J. Richter, J. Porphyrins Phthalocyanines, 2004, 8, 934; (d) Y. S. Xie, J. P. Hill, A. L. Schumacher, Atula S. D. Sandanayaka, Y. Araki, P. A. Karr, J. Labuta, F. D'Souza, O. Ito, C. E. Anson, A. K. Powell and K. Ariga, J. Phys. Chem. C, 2008, 112, 10559.

9 (a) M. E. Kosal and K. S. Suslick, J. Solid State Chem., 2000, 152, 87; (b) F. Scandola, C. Chiorboli, A. Prodi, E. Iengo and E. Alessio, Coord. Chem. Rev., 2006, 250, 1471.

10 E. Y. Choi, C. A. Wray, C. Hu and W. Choe, CrystEngComm, 2009, 11, 553.

11 M. E. Kosal, J. H. Chou, S. R. Wilson and K. S. Suslick, Nat. Mater., 2002, 1, 118.

12 H. J. Son, S. Jin, S. Patwardhan, S. J. Wezenberg, N. C. Jeong, M. So, C. E. Wilmer, A. A. Sarjeant, G. C. Schatz, R. Q. Snurr, O. K. Farha, G. P. Wiederrecht and J. T. Hupp, J. Am. Chem. Soc., 2013, 135, 862.

13 (a) O. K. Farha, A. M. Shultz, A. A. Sarjeant, S. T. Nguyen and J. T. Hupp, J. Am. Chem. Soc., 2011, 133, 5652; (b) R. W. Larsen, L. Wojtas, J. Perman, R. L. Musselman, M. J. Zaworotko and C. M. Vetromile, J. Am. Chem. Soc., 2011, 133, 10356; (c) D. H. Lee, S. Kim, M. Y. Hyun, J. Y. Hong, S. Huh, C. Kim and S. J. Lee, Chem. Commun., 2012, 48, 5512.

14 (a) H. Krupitsky, Z. Stein, I. Goldberg and C. E. Strouse, J. Inclusion Phenom. Mol. Recognit. Chem., 1994, 18, 177-192; (b) P. Dastidar, Z. Stein, I. Goldberg and C. E. Strouse, Supramol. Chem., 1996, 7, 257-270.

15 (a) I. Goldberg, CrystEngComm, 2002, 4, 109-116; (b) I. Goldberg, Chem. Commun., 2005, 1243-1254; (c) N. Zheng, J. Zhang, X. Bu and P. Feng, Cryst. Growth Des., 2007, 7, 2576; (d) I. Goldberg, CrystEngComm, 2008, 10, 637-645; (e) R. W. Seidel, R. Goddard, K. Föcker and I. M. Oppel, CrystEngComm, 2010, 12, 387-394; $(f)$ R. W. Seidel and I. M. Oppel, CrystEngComm, 2010, 12, 1051-1053.

16 F. H. Allen, The Cambridge Structural Database, Acta Crystallogr., Sect. B: Struct. Sci., 2002, 58, 380-388.

17 S. George, S. Lipstman and I. Goldberg, Cryst. Growth Des., 2006, 12, 2651.

18 (a) H. L. Jiang, D. Feng, J. R. Li, T. F. Liu and H. C. Zhou, J. Am. Chem. Soc., 2012, 134, 14690; (b) A. Schaate, P. Roy, A. Godt, J. Lippke, F. Waltz, M. Wiebcke and M. P. Behrens, Chem. - Eur. J., 2011, 17, 6643.

19 M. Kim and S. M. Cohen, CrystEngComm, 2012, 14, 4096-4104.

20 D. Feng, Z. Y. Gu, J. R. Li, H. L. Jiang, Z. Wei and H. C. Zhou, Angew. Chem., 2012, 124, 10453-10456.

21 J. An, O. K. Farha, J. T. Hupp, E. Pohl, J. I. Yeh and N. L. Rosi, Nat. Commun., 2012, 3, 604.
22 H. Deng, S. Grunder, K. E. Cordova, C. Valente, H. Furukawa, M. Hmadeh, F. Gandara, A. C. Whalley, Z. Liu, S. Asahina, H. Kazumori, M. O'Keeffe, O. Terasaki, J. F. Stoddart and O. M. Yaghi, Science, 2012, 336, 1018-1023.

23 H. L. Jiang, D. Feng, K. Wang, Z. Y. Gu, Z. Wei, Y. P. Chen and H. C. Zhou, J. Am. Chem. Soc., 2013, 135, 13934-13938.

24 D. Feng, W. C. Chung, Z. Wei, Z. Y. Gu, H. L. Jiang, Y. P. Chen, D. J. Darensbourg and H. C. Zhou, J. Am. Chem. Soc., 2013, 135, 17105-17110.

25 J. H. Cavka, S. Jakobsen, U. Olsbye, N. Guillou, C. Lamberti, S. Bordiga and K. P. Lillerud, J. Am. Chem. Soc., 2008, 130, 13850-13851.

26 M. H. Xie, X. L. Yang and C. D. Wu, Chem. Commun., 2011, 47, 5521.

27 (a) X. Q. Yu, J. S. Huang, W. Y. Yu and C. M. Che, J. Am. Chem. Soc., 2000, 122, 5337; (b) S. M. Ribeiro, A. C. Serra and A. M. Gonsalves, Tetrahedron, 2007, 63, 7885.

28 M. H. Xie, X. L. Yang, C. Zou and C. D. Wu, Inorg. Chem., 2011, 50, 5318-5320.

29 R. Patra, H. M. Titi and I. Goldberg, Cryst. Growth Des., 2013, 13, 1342.

30 S. Lipstman and I. Goldberg, Cryst. Growth Des., 2013, 13, 942.

31 E. Y. Choi, L. D. DeVries, R. W. Novotny, C. Hu and W. Choe, Cryst. Growth Des., 2010, 10, 171.

32 S. Lipstman and I. Goldberg, Cryst. Growth Des., 2010, 10, 5001.

33 X. S. Wang, L. Meng, Q. Cheng, C. Kim, L. Wojtas, M. Chrzanowski, Y. S. Chen, X. P. Zhang and S. Ma, J. Am. Chem. Soc., 2011, 133, 16322-16325.

34 S. Matsunaga, N. Endo and W. Mori, Eur. J. Inorg. Chem., $2012,4885$.

35 L. Meng, Q. Cheng, C. Kim, W. Y. Gao, L. Wojtas, Y. S. Chen, M. J. Zaworotko, X. P. Zhang and S. Ma, Angew. Chem., Int. Ed., 2012, 51, 10082-10085.

36 X. L. Yang, M. H. Xie, C. Zou, Y. He, B. Chen, M. O Keeffe and C. D. Wu, J. Am. Chem. Soc., 2012, 134, 10638-10645.

37 X. S. Wang, M. Chrzanowski, C. Kim, W. Y. Gao, L. Wojtas, Y. S. Chen, X. P. Zhang and S. Ma, Chem. Commun., 2012, 48, 7173-7175.

38 J. J. Perry, J. A. Perman and M. J. Zaworotko, Chem. Soc. Rev., 2009, 38, 1400-1417.

39 X. S. Wang, M. Chrzanowski, W. Y. Gao, L. Wojtas, Y. S. Chen, M. J. Zaworotko and S. Ma, Chem. Sci., 2012, 3, 2823.

40 X. S. Wang, M. Chrzanowski, L. Wojtas, Y. S. Chen and S. Ma, Chem. - Eur. J., 2013, 19, 3297-3301.

41 J. A. Johnson, Q. Lin, L. C. Wu, N. Obaidi, Z. L. Olson, T. C. Reeson, Y. S. Chen and J. Zhang, Chem. Commun., 2013, 49, 2828.

42 Q. Zha, C. Ding, X. Rui and Y. S. Xie, Cryst. Growth Des., 2013, 13, 4583.

43 (a) P. Kogerler and L. Cronin, Angew. Chem., Int. Ed., 2005, 44, 844; (b) J. X. Meng, Y. Lu, Y. G. Li, H. Fu and E. B. Wang, Cryst. Growth Des., 2009, 9, 4116; (c) A. Dolbecq, E. Dumas, C. R. Mayer and P. Mialane, Chem. Rev., 2010, 110, 6009.

44 (a) R. Yu, X. F. Kuang, X. Y. Wu, C. Z. Lu and J. P. Donahue, Coord. Chem. Rev., 2009, 253, 2872; (b) U. Kortz, A. Müller, 
J. van Slageren, J. Schnak, N. S. Dalal and M. Dressel, Coord. Chem. Rev., 2009, 253, 2315.

45 (a) M. D. McGehee and A. J. Heeger, Adv. Mater., 2000, 12, 1655; (b) H. E. Katz, Z. Bao and S. L. Gilat, Acc. Chem. Res., 2001, 30, 359; (c) S. Pramanik, C. Zheng, T. J. Emge and J. Li, J. Am. Chem. Soc., 2011, 133, 4153; (d) A. Lan, K. Li, H. Wu, D. H. Olson, T. J. Emge, W. Ki, M. Hong and J. Li, Angew. Chem., Int. Ed., 2009, 48, 2334.

46 D. Hagrman, P. J. Hagrman and J. Zubieta, Angew. Chem., Int. Ed., 1999, 38, 3165.

47 C. Zou, Z. Zhang, X. Xu, Q. Gong, J. Li and C. D. Wu, J. Am. Chem. Soc., 2012, 134, 87.

48 M. H. Alkordi, Y. Liu, R. W. Larsen, J. F. Eubank and M. Eddaoudi, J. Am. Chem. Soc., 2008, 130, 12639.
49 E. Y. Choi, C. A. Wray, C. Hu and W. Choe, CrystEngComm, 2009, 11, 553.

50 A. M. Shultz, O. K. Farha, J. T. Hupp and S. T. Nguyen, J. Am. Chem. Soc., 2009, 131, 4204.

51 C. Y. Lee, O. K. Farha, B. J. Hong, A. A. Sarjeant, S. T. Nguyen and J. T. Hupp, J. Am. Chem. Soc., 2011, 133, 15858.

52 C. Guo, J. Song, X. Chen and G. J. Jiang, J. Mol. Catal. A: Chem., 2000, 157, 31-40.

53 Z. Zhang, L. Zhang, L. Wojtas, P. Nugent, M. Eddaoudi and M. J. Zaworotko, J. Am. Chem. Soc., 2012, 134, 924.

54 Z. Zhang, W. Gao, L. Wojtas, S. Ma, M. Eddaoudi and M. J. Zaworotko, Angew. Chem., 2012, 124, 9464.

55 Z. Zhang, L. Wojtas, M. Eddaoudi and M. J. Zaworotko, J. Am. Chem. Soc., 2013, 135, 5982. 